\title{
Wage bargaining, working time and unemployment
}

\author{
Citation for published version (APA):
}

de Regt, E. R. (1999). Wage bargaining, working time and unemployment. METEOR, Maastricht University School of Business and Economics. METEOR Research Memorandum No. 027 https://doi.org/10.26481/umamet.1999027

Document status and date:

Published: 01/01/1999

DOI:

10.26481/umamet.1999027

Document Version:

Publisher's PDF, also known as Version of record

\section{Please check the document version of this publication:}

- A submitted manuscript is the version of the article upon submission and before peer-review. There can be important differences between the submitted version and the official published version of record.

People interested in the research are advised to contact the author for the final version of the publication, or visit the DOI to the publisher's website.

- The final author version and the galley proof are versions of the publication after peer review.

- The final published version features the final layout of the paper including the volume, issue and page numbers.

Link to publication

\footnotetext{
General rights rights.

- You may freely distribute the URL identifying the publication in the public portal. please follow below link for the End User Agreement:

www.umlib.nl/taverne-license

Take down policy

If you believe that this document breaches copyright please contact us at:

repository@maastrichtuniversity.nl

providing details and we will investigate your claim.
}

Copyright and moral rights for the publications made accessible in the public portal are retained by the authors and/or other copyright owners and it is a condition of accessing publications that users recognise and abide by the legal requirements associated with these

- Users may download and print one copy of any publication from the public portal for the purpose of private study or research.

- You may not further distribute the material or use it for any profit-making activity or commercial gain

If the publication is distributed under the terms of Article $25 \mathrm{fa}$ of the Dutch Copyright Act, indicated by the "Taverne" license above, 
Universiteit Maastricht

Department of Economics

\title{
Wage Bargaining, Working Time and Unemployment
}

\author{
Erik de Regt ${ }^{*}$
}

November 1999

\begin{abstract}
The paper analyses the impact of working time (reduction) on wages and unemployment. Using a union bargaining framework, I show that working time reduction leads to wage moderation in terms of annual remuneration. This result is independent of the bargaining regime, as it holds for the right-to-manage model and for the efficient bargaining model. As a result, the relation between hourly wages and working time is likely to be U-shaped. The level of working time where the impact of hours on hourly wages changes sign, is typically higher than the individual hours supply, unless the latter is strongly upward sloping. Extending these partial equilibrium results to the general equilibrium, this also leads to a U-shaped relation between equilibrium unemployment and working time: For relatively long working times, a reduction in working time will decrease the unemployment rate; whereas unemployment may increase for shorter working times.
\end{abstract}

JELclassification: J23, J30, J51

Keywords: wage bargaining, working time, unemployment.

Address:

E.R. de Regt

P.O. Box 616

6200 MD Maastricht

the Netherlands

e-mail: e.deregt@algec.unimaas.nl

* I thankJ oan Muysken for comments. All errors and ambiguities are mine. 


\section{Wage Bargaining, Working Time and Unemployment}

\section{Introduction}

Work-sharing is a recurring theme in the European unemployment debate. Every now and then at times of high unemployment, the suggestion is made to reduce working times as to redistribute the available work. Recent examples are France and Italy, where in 1997 the newly elected socialist Jospin and Prodi governments suggested to reduce weekly hours to 35 at the beginning of the new millennium. In France a law has been enacted to implemented this reduction in 2000. Early adopting firms got deductions on their social premiums to provide incentives. In the early eighties a similar attempt by Mitterand was considered a failure, see Hunt (1998).

In Germany and the Netherlands, similar discussions were observed in the eighties. In these countries, however, the work-sharing debate must be considered in the context of labour relations. Unions, instead of governments, pressed for reduced hours. After the first two oil shocks in the seventies, the Dutch economy was in disarray. ${ }^{1}$ Unemployment increased rapidly, reaching its highest level of about $10 \%$ in 1983. The government and the social partners felt the urge for changes. This lead to consultations and in October 1982 the famous Wassenaar Agreement was struck. One of the main recommendations was for unions to moderate wage claims in exchange for increases in employment and reductions in working time. Except as employer in the public sector, the government was not directly involved in the agreement, but it would facilitate the wage moderation by striving at general tax reductions. Since then annual full-time working time has fallen by roughly 100 hours, partly as a reduction in weekly hours from 40 to 38 hours (36 in the public sector) and partly by an increase in holidays. Moreover wages have been moderated and the wedge has been reduced. In the second half of the nineties, this sustained policy was considered a success and was referred to as the Dutch miracle.

The economics literature has been rather sceptical towards the merits of work-sharing policies. The major argument is the so-called lump-of-labour fallacy, see Layard, Nickell et al. (1991, Ch. 10). This critique refutes the idea that there is a fixed amount of work that can be redistributed at will. On the contrary, employment is determined by demand and supply factors. The impact of working time may occur through various channels, see Freeman (1998) and Hunt (1998) for recent discussions. ${ }^{2}$ The main ones are:

- Labour productivity per hour may change, although the direction is ambiguous. First, the share of non-productive hours increases, reducing hourly productivity, but second, reduced fatigue works in the opposite direction (Booth and Ravallion (1993)).

- Wage costs per hour increase through the existence of fixed costs per employee. Beside the direct negative effect on the demand for labour (worker-hours), this provides an incentive to use more overtime and to substitute away from workers (Hart (1984b), Hunt (1999)).

- Capital utilization will decrease, at least to the degree that the operating time of the capital stock is linked to the working time of workers (Calmfors and Hoel (1989)). This leads to an increase in production costs and a reduction of labour demand.

1 The German case is discussed in Hunt (1998).

2 Further references can be found in the surveys by Corneo (1994) and Houpis (1993). 
- Hourly wage rates may increase in an attempt to protect real incomes. This may occur due to union wage setting (Calmfors (1985)) or to efficiency wage considerations (Hoel and Vale (1986)).

- Labour supply, i.e. participation in the labour market, may change, although the direction is ambiguous and depends on desired hours (Hunt (1998)).

Taking these factors together, the general equilibrium effects of work-sharing on unemployment are puzzling. Layard, Nickell et al. (1991, Ch. 10) claim that equilibrium unemployment is unaffected by work-sharing. However, as their model does not incorporate working time and leisure as separate elements, this conclusion seems doubtful. In the efficiency wage model of Hoel and Vale (1986) the unemployment rate will increase if working time is reduced, but they also ignore the utility of leisure. Cahuc and Granier (1997) do take this into account, and conclude that equilibrium unemployment is unaffected by work-sharing policies. The current paper elaborates on these issues. The new conclusion is that there is a U-shaped relation between equilibrium unemployment and working time. Recently, Moselle (1996) obtained a similar result in an efficiency wage model.

The paper can be considered as an elaboration of the seminal paper by Calmfors (1985). That paper considers a partial equilibrium monopoly union model. I extend the model in a number of directions to incorporate most of the above issues and to derive general equilibrium results. As in Calmfors (1985) I do not include overtime into the analysis, but assume that cuts in standard hours translate almost one for one into reductions of actual hours. Hunt (1999) confirms this for Germany and I found a similar result for the Netherlands (De Regt (1988), see also Hunt (1998)). In the labour demand model I do incorporate a dependence of capital services on the working time of workers. This reduces the scope of work-sharing policies. This is reinforced by a focus on long-run adjustment, where the capital stock is allowed to adjust.

With respect to the wage bargaining, I extend the monopoly union results of Calmfors (1985) towards right-to-manage and efficient bargaining models. As working time is assumed to be given exogenously, wage bargaining can be described in terms of hourly wages or in terms of total remuneration. It turns out that the latter is easier, but I will briefly describe the impact on hourly wages to compare with Calmfors. For hourly wages, the results of my partial equilibrium analysis are fairly in line with his results, but I suggest a more intuitive interpretation. Even though hourly wage may increase as a consequence of working time reduction, my results indicate that annual remuneration is likely to fall. The partial equilibrium employment effects are ambiguous and depend on the initial working time: for long hours employment increases, but for short hours employment falls.

In the general equilibrium, I find similar results, leading to the U-shaped relation between unemployment and working time.

The paper is organized as follows. Section 2 introduces the partial equilibrium right-to-manage union model, where capital services are explicitly taken into account. Section 3 describes the impact of reduced working time within this model. This gives a generalization of the results by Calmfors. In section 4 I show that the impact of reduced working time is rather similar in an efficiency bargaining framework. Section 5 then considers the general equilibrium of the right-to-manage model. I provide a numerical illustration of the partial and general equilibrium models in Section 6 and conclude in the final section 7 . 


\section{The partial equilibrium model}

\subsection{Firms}

Firms are operating in a monopolistically competitive output market. I do not consider entry, so the number of firms is fixed. For the partial equilibrium this assumption is innocuous, but it may affect the general equilibrium results. A typical firm in the industry faces a downward sloping iso-elastic demand curve of the type $Y=P^{-\hat{o}} D$, where $Y$ is the output of the firm, $P$ is its price, $D$ is a demand shift variable and $\hat{o}>1$ is the elasticity of demand. The demand shifter $D$ may well depend on the aggregate price level, but for the present analysis it can, without loss of generality, be set equal to unity. With this demand function, the revenue $Q$ of the firm is given by $Q=P Y=Y^{1}$, where $0<1 \equiv 1-1 / \hat{o}<1$ measures the competitiveness of the output market. Perfect competition corresponds to the limiting case $1=1$, and for lower values the firm specific demand curve becomes steeper.

Firms produce their output with capital and labour as the only two production factors. Beside the stocks of these inputs, capital $K$ and employment $N$, the duration of operation matters. Ignoring shiftwork, the operating time of the capital stock is equal to the working time $H$ of labour. This would imply that labour services $L$ are given by worker-hours $E \equiv N H$, whereas capital services are equal to $M$ $=K H$. To incorporate warming-up times and fatigue effects, it is often suggested, see e.g., Andersen (1987), Booth and Ravallion (1993) and De Regt (1999b), to replace working time in labour services by so-called efficiency hours $e(H)$. I assume that, at least in the relevant range of working hours, efficiency hours are increasing in working time, though probably at a decreasing rate, so $e^{\prime \prime}(\cdot)<0<e^{\prime}(\cdot)$. More specifically, I assume that the elasticity of efficiency hours with respect to working time $c^{e}$ is nonincreasing in working time. ${ }^{3}$ This captures that workers get tired if they work long hours.

For the sake of analytical convenience, I also replace working time in capital services by efficiency hours. As shown in De Regt (1999b), the crucial assumption is that working time affects capital services. Allowing for different efficiency hours in capital and labour services, see De Regt (1988), complicates the algebra but does not yield qualitatively different results.

Combining these assumptions with a linear homogeneous production function $F(\cdot)$ in capital and labour services, output is given by

$$
Y=F(K e(H), N e(H))=e(H) N f(k),
$$

where $k \equiv K / N$ is the capital-labour ratio, measured in bodies, and $f(k) \equiv F(k, 1)$ is the per capita instantaneous production function, satisfying $f^{\prime \prime}(k)<0<f^{\prime}(k)<f(k) / k$. On the one hand, output depends on the duration of operations, see Georgescu-Roegen (1970), as characterized by efficiency hours. On the other hand, the instantaneous production function characterizes the substitution possibilities between the stocks, the substitution elasticity being $o^{\prime} \equiv \frac{f^{\prime}(k)\left[f(k)-k f^{\prime}(k)\right]}{k f(k) f^{\prime \prime}(k)}>0$. The scale of operation is determined by the number of workers. This specification looks like a kind of putty-clay assumption: at

3 This is, for example, the case for the translog specification $\ln e(H)=\tilde{\mathrm{a}}_{0}+\tilde{\mathrm{a}}_{1} \ln H-1 / 2 \tilde{\mathrm{a}}_{2}(\ln H)^{2}$, with $0<\tilde{\mathrm{a}}_{1}$ and $0 \leq \tilde{\mathrm{a}}_{2}$, where $c^{e}=\tilde{\mathrm{a}}_{1}-\tilde{\mathrm{a}}_{2} \ln H$. Another reason may be the existence of fixed non-productive time $S \geq 0$. For example, let $e(H)=(H-S)^{\tilde{a}}$, with ã $>0$, then $c^{e}=\tilde{a} H /(H-S)$ and $\partial c^{e} / \partial H=-\tilde{a} S /(H-S)^{2} \leq 0$. 
the beginning of the day (or week), the capital-labour ratio is chosen, and this ratio is maintained throughout the day; output per capita then depends on the efficiency hours; and the scale of operation is determined by the number of bodies $N$.

In this paper working time is considered fixed for the firms. It is best interpreted as standard hours either set by the government or, more realistically, determined in the bargaining between firms and unions, see De Regt (1999a). Moreover, I assume that firms do not use overtime. Although the impact of reductions in working time on employment may depend on the use of overtime, see e.g., Freeman (1998) and Hart (1984b), the evidence seems to suggest that actual hours vary proportionally with standard hours, see Hunt (1998).

With this set-up, labour costs consist of two parts: First, the hourly wage costs $W$ and second quasifixed labour costs $V$. The latter are independent of the number of hours and may consist of discounted training costs, holiday and sick payment, taxes (due to ceilings) etc, see Hamermesh (1993, Ch. 2) or Hart (1984a) for a discussion. Given the absence of overtime hours, total remuneration per worker corresponds to $C=W H$. As the firm also incurs fixed costs, labour costs per worker are $P_{N}=V+C$. For future reference, the share of fixed costs in labour costs is denoted $\varphi_{V} \equiv V / P_{N}$. Finally, the user costs of capital are exogenously given by $R$. It is thus assumed that operating time of capital does not influence these costs. ${ }^{4}$ Given the above assumptions, the profit of an individual firm can be written as $Đ$ $=Y^{\prime}-(V+W H) N-R K$.

In De Regt (1999b) I have shown that it is important to include the optimal determination of the capital stock when considering the impact of reduced hours on the demand for labour. The reason is that working time affects capital services in my specification of the production function. Hence working time reductions make capital less productive and may reduce capital formation. Taking the capital stock fixed, as in Calmfors (1985), may thus overstate the potential for work-sharing policies. Therefore, I concentrate on the opposite extreme where the capital stock may be adjusted freely. In footnotes I will show, however, that the qualitative outcomes for the short-run model with fixed capital stock are rather similar. A numerical illustration is given in section 6 .

Maximizing the profit with respect to the capital stock $K$ and number of workers $N$ gives the firstorder conditions

$$
\begin{gathered}
0=\bigoplus_{K}=1 e(H)^{1} N^{\hat{1}-1} f(k)^{\hat{1}-1} f^{\prime}(k)-R, \\
0=\bigoplus_{N}=\text { í } e(H)^{\hat{1}} N^{1-1} f(k)^{\hat{1}-1}\left[f(k)-k f^{\prime}(k)\right]-(V+C) .
\end{gathered}
$$

The second-order conditions for profit maximization $1<1$ and ó $>0$ are satisfied. Dividing the firstorder conditions, the capital-labour ratio is determined independently of the scale as

$$
\frac{f^{\prime}(k)}{f(k)-k f^{\prime}(k)}=\frac{R}{V+C} .
$$

4 In De Regt (1999c) I allow for dependence of user costs on the operating time. 
The optimal capital-labour ratio only depends on working time through its impact on total remuneration C.

Combining equations (3) and (4), the long-run labour demand elasticity with respect to remuneration is given by

$$
\varepsilon_{N C}=-\left(1-\varphi_{V}\right)\left[\hat{o}\left(1-c_{\zeta}^{f}\right)+o ́ c ̧{ }^{f}\right]<0,
$$

where $0<c^{f} \equiv k f^{\prime}(k) / f(k)<1$ is the elasticity of the per capita instantaneous production function. ${ }^{5}$ Given the optimal capital-labour ratio in (4), ç ${ }^{f}$ also corresponds to the share capital costs in total costs. The first term in the right-hand side of (5) measures the impact of remuneration on labour costs; labour costs increase less then proportionally through the existence of quasi-fixed costs $V$. The second term between brackets measures the elasticity of labour demand with respect to labour costs. As usual in Marshallian rules of factor demand, it consists of a substitution and a scale effect.

The labour demand function is depicted as $n^{d}$ in the right panels of Figure 1. The figure uses small letters to denote natural logarithms of the corresponding variables. The upper panels use total remuneration $C$ as the relevant wage cost variable, whereas the lower panels use the hourly wage rate $W$. As working time is given, this makes no difference for labour demand and we can either use the upper or lower panels. Given the use of logarithms, the slope of the labour demand curve is the reciprocal of the elasticity $\varepsilon_{N C}$.

The logarithmic labour demand curve $n^{d}$ is concave in Figure 1. This is because the absolute value of the labour demand elasticity $\varepsilon_{N C}$ increases with the level of remuneration $C$. The reason is twofold: First, with higher remuneration the share of quasi-fixed costs in labour costs $\varphi_{V}$ falls; second, higher remuneration changes the optimal share of labour costs in total costs. The sign of the latter effect depends on the size of the elasticity of substitution o. This is best illustrated assuming that the substitution elasticity is constant. ${ }^{6}$ The relative change in the labour demand elasticity is then given by

$$
\ddot{\varepsilon}_{N C} \equiv \frac{C}{\varepsilon_{N C}} \frac{d \varepsilon_{N C}}{d C}=\varphi_{V}+\left(1-\varphi_{V}\right) \frac{(1-\hat{o})(\hat{o}-\hat{o}) c^{f}\left(1-c^{f}\right)}{\hat{o}\left(1-c^{f}\right)+o ́ c^{f}}
$$

Almost all of the evidence, see Hamermesh (1993, Ch. 3), suggests that ó $\leq 1$. For the Netherlands, recent evidence suggests that ó is rather low, see Broer, Draper et al. (1999). Accordingly, I assume that $o ́ \leq 1$. Hence, both terms are positive and $0<\varphi_{V} \leq \ddot{\varepsilon}_{N C}<1 .^{7}$ In the limiting case of a Cobb-

5 For functions of one variable, say $y=g(x)$, I denote the elasticity as ç $c^{g}=x g^{\prime}(x) / g(x)$.

6 Strictly speaking, this only holds for CES instantaneous production functions. For the more general case, we need to impose restrictions on $f^{\prime \prime \prime}(k)$ to derive definite results on the concavity of the logarithmic labour demand function.

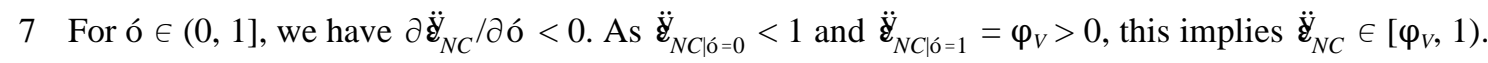


Douglas production function, the last term vanishes. Equation (6) illustrates that the logarithmic labour demand function is concave to the origin, at least for ó $\leq 1{ }^{8}$

\subsection{Worker utility}

All agents in the economy have an identical utility function in terms of consumption and leisure. In our static set-up, there is no saving, and consumption is equal to income. Hence $C$ stands both for total remuneration and for consumption. Agents can be in three different states: They can be employed, unemployed or not participating. This section only considers workers employed in a specific firm. If not employed in this firm, their outside option is given as $U^{a}$ in utility terms. This outside option will be specified in the general equilibrium analysis of section 5 , but is exogenous in the partial equilibrium framework.

Workers can only be employed full-time at a fixed working time $H$, earning $C$. Their utility is then given by $U(C, H)$, with partial derivatives $U_{H}<0<U_{C}$, as agents enjoy consumption and leisure. It will be useful to parameterize the utility function and to put some more structure than in Calmfors (1985). The rate of relative risk aversion for consumption satisfies $a_{C} \equiv-C U_{C C} d U_{C} \geq 0$. Leisure is assumed to be a normal good, implying $a_{C H} \equiv H U_{C H} / U_{C}<a_{C}$. The sign of á ${ }_{C H}$ determines whether consumption and leisure are Edgeworth substitutes ( $\left.a_{C H}>0\right)$ or complements (á $\left.{ }_{C H}<0\right)$.

If workers would be free to choose hours worked, their desired or notional hours $H^{s}$ would be determined by $W U_{C}+U_{H}=0$, or ù $\equiv-U_{H} /\left(W U_{C}\right)=1$. Notice that ù $\lessgtr 1$ for $H \lessgtr H^{s}$, indicating that ù increases with working time. So as guaranteed by the second-order condition of utility maximization, $\partial \mathrm{ù} / \partial H>0 .^{9}$ As will become clear in the sequel, an important parameter of the utility function is the relative change in ù due to changes in the consumption (or in the hourly wage) $\ddot{\mathbf{y}}_{C} \equiv \frac{\partial \ln u ̀}{\partial \ln C}=$ $\mathfrak{a}_{C}-1-\mathfrak{a}_{C H} / \mathrm{ù}$. It is equal to zero for a Cobb-Douglas utility function.

To derive more specific results, I need to assume that consumption and leisure are not too strong Edgeworth complements. A sufficient, although not necessary, condition will be that

$$
U_{C H} \geq \frac{U_{C} U_{H}}{U}
$$

This sets a (negative) lowerbound for the parameter $a_{C H}$. It is easily checked that the condition holds for a Cobb-Douglas utility function and for additive separable specifications in consumption and leisure. For a CES-utility function, however, condition (7) is violated if the elasticity of substitution between consumption and leisure is below one.

8 For the short-run labour demand, at given capital stock $K$, the conditional elasticity is given by $\varepsilon_{N C \mid K}=$ $-\left(1-\varphi_{V}\right) \frac{\hat{o o ́}}{\hat{o} c^{f}+o ́\left(1-c^{f}\right)}$. Hence $\varepsilon_{N C}<\varepsilon_{N C \mid K}<0$. The relative change in this elasticity is given by $\ddot{\dot{\varepsilon}}_{N C \mid K}=$ $\varphi_{V}-\varepsilon_{N C \mid K} \frac{(1-\hat{o})(\hat{o}-\hat{o}) c^{f}\left(1-c_{\zeta}^{f}\right)}{\left[\hat{o} c^{f}+o ́\left(1-c^{f}\right)\right] o ́}>0$. As a consequence, the logarithmic short-run labour demand function is also concave.

9 Although this only needs to hold around $H^{s}$. 
The left panels of Figure 1 illustrate the properties of the utility function of an employed worker. The left-upper panel uses total remuneration (or consumption) $C$ as the relevant variable. To be willing to work in the firm under consideration, the utility level has at least be equal to $U^{a}$, as is for example the case for the indifference curve $U^{m}$. Along an indifference curve, there is a positive relation between consumption $C$ and working time $H$. The slope corresponds to the marginal rate of log substitution ù = $-\left(H U_{H}\right) /\left(C U_{C}\right)>0$. As $\partial \mathrm{ù} / \partial H>0$, the indifference curves are convex.

The left-lower panel of Figure 1 illustrates the same properties, but with the hourly wage $W$ as the dependant variable. The main difference is that the indifference curves have a minimum at the optimal hours $H^{s}$. To simplify, the graph assumes that hours supply is fully inelastic. In general, however, the slope of the hours supply function is indeterminate and is given by the sign of $1-a_{C}+a_{C H}$.

\subsection{Monopoly union wage setting}

Employment at each firm in the economy is unionised. The firms retain their right-to-manage power and determine employment (and capital) after the wage has been set. The assumption that capital is determined after the wage setting, implies that firms cannot pre-commit on the capital stock. Manning (1994) has shown that the timing of the capital stock decision might change the comparative statics of the model. To simplify the model, I abstract from strategic behaviour in the determination of capital. As labour demand is more elastic in this case, this will reduce wage claims.

The specification of the union utility function is an awkward business, see Pencavel (1991, Ch. 3) for a discussion. Obviously, union utility incorporates, among others, employment possibilities, incomes and leisure. For the present purpose, I assume that the utility Ã of a typical union is given by the StoneGeary function

$$
\tilde{\mathrm{A}}=N^{\grave{\mathrm{e}}}\left[U(C, H)-U^{a}\right] . \quad \text { è }>0
$$

The union wants to increase the utility of its employed members above the given outside option $U^{a}$, but also cares about employment $N$. The parameter è is an indicator of the weight put on employment. For è $=1$, this specification generates the same outcomes as the expected or utilitarian utility function used by Booth and Ravallion (1993), Calmfors (1985) and Houpis (1993).

For illustrative purposes, I start with the monopoly union model, where the union sets the wage level as to maximize its utility. This assumption corresponds to Calmfors (1985) and allows me to present a graphical analysis in Figure 1.

At given working time, maximizing union utility with respect to the hourly wage $W$ is equivalent to maximizing with respect to total remuneration $C$. Maximizing the (log of the) union utility function (8), subject to the labour demand in (3) and (4), with respect to remuneration gives the condition

$$
\frac{1}{\varepsilon_{N C}}=-\frac{\mathrm{è}\left[U(C, H)-U^{a}\right]}{C U_{C}(C, H)} .
$$

The left-hand side is the slope of the logarithmic labour demand curve, which corresponds to the inverse of the labour demand elasticity. The right-hand side is the slope of the union indifference curve in the 
log-remuneration and log-employment space. It corresponds to minus the ratio of the utility rent per unit income $\left(U-U^{a}\right) / C$ of additional workers, weighted by the value è unions attach to employment, and the marginal utility $U_{C}$ of consumption of employed workers.

In models ignoring working time, see e.g., Layard, Nickell et al. (1991), utility is typically replaced

by total remuneration, thus $U=C$. In that case, the first-order condition implies $\frac{C}{\grave{\mathrm{e}}\left(C-C^{a}\right)}=-\varepsilon_{N C}$ and the remuneration set by the union is a mark-up on the outside option $C^{a}$. This simple interpretation is no longer valid in (9), as working time plays its own role. A more general interpretation is suggested by Houpis (1993). He argues that (9) implies that the individual utility $U^{m}$ set by unions is a mark-up on the outside utility $U^{a}$. Strictly speaking, however, this interpretation is only valid if the elasticity of utility with respect to consumption $C U_{C} d U$ is constant. This basically restricts the utility function to a Cobb-Douglas utility function. For other specifications no such a simple interpretation is available, although (9) obviously implies $U^{m}>U^{a}$.

The above partial equilibrium solution is illustrated in Figure 1. The right-upper panel illustrates that union indifference curves are downward sloping. It has an asymptote for $C^{a}$, implicitly defined by $U^{a}=$ $U\left(C^{a}, H\right)$, as the utility for employed workers should not fall below the outside option. At the equilibrium $M$, as identified by equation (9), the union indifference curve $\tilde{\mathrm{A}}^{m}$ is tangent to the labour demand curve. From the left panels, observe that employed workers have utility $U^{m}$. In a competitive labour market with fixed working time the resulting allocation would be $A$, because workers would be forced to accept their outside option.

The same partial equilibrium is again illustrated in the lower panels, but with the hourly wage on the vertical axis. The asymptote is given by $W^{a}=C^{a} / H$, but the remaining part of the figure is very similar. In the left-lower figure the indifference curves are U-shaped; the minimum corresponding to the optimal hours. The figure considers the case of underemployed workers ( $\mathrm{u}<1)$.

The second-order condition for wage determination ensures that in the right panels of Figure 1 the union indifference curve is less concave than the labour demand curve.

\section{$2.4 \quad$ Right-to-manage bargaining}

The monopoly union model is a special case of right-to-manage bargaining framework and it is easy to extend the analysis in this direction. The wage bargaining game is not modelled explicitly. As usual in the literature on wage formation, see e.g., Layard, Nickell et al. (1991), I assume that the outcome of the bargaining process can be found by maximizing an asymmetric Nash function. The Nash-maximand is given by

$$
\grave{\mathrm{U}}=(\tilde{\mathrm{A}}-\underline{\tilde{\mathrm{A}}})(Đ-\underline{\mathrm{D}})^{\hat{\mathrm{a}}}, \quad \quad \hat{\mathrm{a}} \geq 0
$$

where â measures the bargaining power of firms, insofar not reflected in their fallback options $\underline{\tilde{A}}$ and $\underline{\nsupseteq}$. For $\hat{a}=0$ the model reduces to the above monopoly union model. In the long-run model, both threatpoints are set equal to zero, hence the Nash-maximand reduces to $\grave{U}=\tilde{A} \bigoplus^{\hat{a}}$. For the union this implies that workers are able to obtain the outside utility $U^{a}$ during a strike, for the firm this is consistent with 
the (admittedly unrealistic) hypothesis that the capital stock can be adjusted freely after completion of the wage bargain. ${ }^{10}$

The outcome of the wage bargain is most easily obtained differentiating the log of the Nashmaximand with respect to remuneration. After rearranging, this yields the first-order condition

$$
\frac{C U_{C}}{U-U^{a}}=\mu_{C} \equiv-\grave{e ̀} \varepsilon_{N C}-\hat{a} \varepsilon_{Đ C}
$$

where $\varepsilon_{Ð C}$ is the elasticity of profits with respect to remuneration. This is a straightforward generalisation of equation (9) for the monopoly union. The left-hand side is the increase in utility rent for employed workers. The first term on the right-hand side is due to the right-to-manage assumption. It is the impact of wages on employment, weighted by the value unions attach to employment. The final term is due to the bargaining power of firms and captures employer resistance due to lower profits. As the right-hand side also incorporates wage resistance by employers, I will call the coefficient $\mu_{C}$ wage resistance. It consists of two parts: The first part operates through the union preference for work, as in the monopoly union model; the second part, involving $\hat{a}$, is the employer resistance in the wage bargaining process. The more bargaining power â firms have, the higher is their resistance to wage hikes.

In terms of the right panels of Figure 1, the outcome will be on the labour demand curve $n^{d}$ somewhere between $M$ and $A$. As â increases, wage resistance increases and we move downwards along the labour demand curve. The competitive outcome $A$, where $U=U^{a}$, results is the limiting case where the firm has all bargaining power $(\hat{\mathrm{a}} \rightarrow \infty)$.

The second-order condition of the wage bargain corresponds to

$$
\ddot{\mathrm{E}}_{C} \equiv \dot{\mathrm{a}}_{C}+\mu_{C}+\ddot{\mathrm{y}}_{C}-1>0 \text {, }
$$

where $\ddot{\mathbf{E}}_{C} \equiv \frac{C}{\mu_{C}} \frac{d \mu_{C}}{d C}$. I assume this condition to be satisfied. It sets a lowerbound on the sum of wage resistance $\mu_{C}$ plus relative risk-aversion of consumption á ${ }_{C}$. This can be interpreted in several ways: First, workers should be sufficiently risk averse with respect to income (á $\left.{ }_{C}\right)$; or second, labour demand should be sufficiently elastic $\left(\varepsilon_{N C}\right)$; or third, unions should put sufficient value on employment (è); or fourth, firms should have sufficient bargaining power (â).

Wage resistance $\mu_{C}$ plays an important role in the model. Therefore, I briefly consider its determinants. Using the model of the firm, wage resistance can be written as

$$
\mu_{C}=\left(1-\varphi_{V}\right) \text { è }\left[o_{\hat{a}}\left(1-c^{f}\right)+o_{c ̧}^{f}\right]>0,
$$

10 In the short-run model the fallback option of the firm is specified as $\underline{Ð}=-R K$. 
where $\delta_{\hat{a}} \equiv \hat{o}(\grave{e}+\hat{a ̂ i}) / \mathrm{è} \geq \hat{o}>1$. So $\mu_{C} \geq-$ èc ${ }_{N C}$ as can be seen comparing (5) and (13) and, as a consequence, remuneration is lower in the right-to-manage model, compared to the monopoly model. From (13) one can check that wage resistance satisfies

$$
\mu_{C}=\mu_{C}\left(\varphi_{V}, \text { è, }, \hat{a}, 1 ́, o ́, k\right),
$$

where the signs below the variables denote the sign of the corresponding partial derivative. For the capital intensity $k$ the sign depends on the elasticity of substitution, being positive for ó $<1$ and equal to zero for the Cobb-Douglas case (ó $=1$ ). The signs of the partial derivatives are as expected. For example, wage resistance is high in more competitive markets (where $1=1-1 / \hat{o}$ is high) and higher quasi-fixed costs $V$ reduce employer resistance, as it makes remuneration $C$ a smaller part of labour costs.

For the total impact of $C$ on wage resistance, we can generalise (6) to

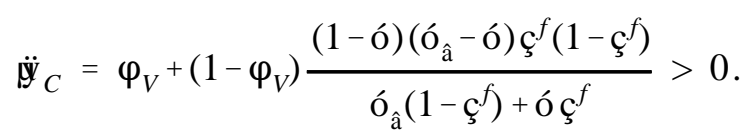

So wage resistance increases with remuneration $C$, although less then proportionally as $\ddot{y}_{C}<1 .{ }^{11}$ Finally, notice that wage resistance does not depend on working time, except for its impact on total remuneration. This is one of the main reasons why it is easier to work in terms of remuneration instead of hourly wages.

\section{Working time reduction}

The partial equilibrium bargaining model can be used to derive the impact of an exogenous reduction in working time on employment, remuneration and hourly wages. I start with a analysis of labour demand, then I illustrate the monopoly union case graphically and finally I turn to the more general right-tomanage model. It turns out that it is most convenient to start with the impact on remuneration, instead of hourly remuneration used by Calmfors (1985). Hourly wages can be derived recursively. This provides more background in the underlying mechanisms.

\subsection{Labour demand}

First, consider the impact on labour demand, see also De Regt (1999b). Due to the inclusion of efficiency hours and their impact on capital services, I am able to get more specific results compared to

11 In the short-run model, with fixed capital stock, the expression for wage resistance becomes:

$$
0<\mu_{C \mid K}=\left(1-\varphi_{V}\right)\left[\frac{\text { è ó }}{c^{f}+o ́(1-\hat{1})\left(1-c^{f}\right)}+\frac{\text { âí }\left(1-c^{f}\right)}{1-\hat{1}\left(1-c^{f}\right)}\right]<\mu_{C} .
$$

Tedious algebra once again shows that its relative change with respect to remuneration satisfies $0<\ddot{\mathbb{y}}_{C \mid K}<$ 1. 
Calmfors (1985), who basically assumes that employment will increase at constant hourly wages. The present model allows me to derive the condition for this to be true. Moreover, the model allows for a neat decomposition in a productivity effect (at given remuneration) and a cost effect (at given efficiency hours).

At given remuneration $C$, a reduction in working time is similar to neutral technological regress. ${ }^{12}$ This is the productivity effect reducing labour demand. It is easy to derive from equations (3) and (4) that the labour demand elasticity with respect to hours is given by $\varepsilon_{N H \mid C}=1 c^{e} /(1-1)>0$. As the elasticity of efficiency hours is non-increasing in working time, the effect is likely to increase for shorter hours. Moreover, the impact is larger in more competitive goods markets. From (5) we also observe that the labour demand elasticity with respect to remuneration remains the same. Hence, the logarithmic labour demand curve $n^{d}$ in the upper-right panel of Figure 1 shifts inward, but keeps the same slope. ${ }^{13}$ This is illustrated in the north-east panel of Figure 2.

At given hourly wages, the impact of reduced hours on labour demand is ambiguous. First, we have the technical regress effect as above, but second, total remuneration falls increasing labour demand. This second cost effect also changes the slope of the labour demand curve, according to equation (6). So in terms of the lower-right panel of Figure 1, the labour demand curve becomes less elastic, but the direction of the shift is ambiguous. Calmfors (1985) assumes that employment will increase at constant hourly wages.

The net elasticity is $\varepsilon_{N H \mid W}=\varepsilon_{N H \mid C}+\varepsilon_{N C}$, which cannot be signed a priori, with both terms of opposite sign. However, the elasticity is negatively related with working time. In the limiting case of $H=0$, the second term vanishes as $\varphi_{V}=1$ in (5). Moreover, the elasticity of efficiency hours $c^{e}$ is at its maximum at $H=0$. Hence, in that case $\varepsilon_{N H \mid W}>0$. Increasing hours leads to a lower $c^{e}$ and, at given hourly wages, to a lower remuneration. Therefore, the wage elasticity $\varepsilon_{N C}$ falls below zero and $\varepsilon_{N H \mid W}$ declines. For sufficiently long hours the net elasticity becomes negative, as its first term is non-increasing and the second term becomes more negative. Let the critical level $H_{n}$ be implicitly defined by $\varepsilon_{N H \mid W}=0$, then $\varepsilon_{N H \mid W} \gtrless 0$ for $H \lessgtr H_{n}$. So, at given hourly wages, labour demand only increases with a working time reduction, if hours are not too short. ${ }^{14}$

The critical level $H_{n}$ depends negatively on the hourly wage rate. ${ }^{15}$ Therefore, the above condition can also be formulated as $\varepsilon_{N H \mid W} \gtrless 0$ for $W \lessgtr W_{n}$. In other words, working time reduction increases labour demand at given hourly wages only if hourly wages are high enough. The intuition for this result is that for low wages the quasi-fixed labour costs become the bulk of labour costs. A reduction in

12 Neutral because, by assumption, efficiency hours affect capital services and labour services in the same way.

13 If (efficiency) hours would only affect labour services, but not capital services, as is assumed in the bulk of the literature, the labour demand curve shifts less, but also becomes more elastic.

14 At given capital stock, we have $\varepsilon_{N H \mid, C}>\varepsilon_{N H \mid K, C}=\frac{(\hat{\mathrm{o}}-1) \text { ó } n^{e}}{\hat{\mathrm{occ}}{ }^{f}+\hat{o}\left(1-\mathrm{c}^{f}\right)}>0$ and $\varepsilon_{N H \mid K, W}=\varepsilon_{N H \mid K, C}+\varepsilon_{N C \mid K}$. This yields qualitatively similar results for the short-run labour demand model.

15 Let $\ddot{\Theta}^{e} \leq 0$ denote the relative change of the elasticity ç $^{e}$ with respect to working time, then $-1 \leq \frac{d \ln H_{n}}{d \ln W}=$ $-\frac{\ddot{\mathfrak{z}}_{N C}}{\ddot{\mathbb{z}}_{N C}-\ddot{\mathfrak{g}}^{e}}<0$. So there is a critical hourly wage level $W_{n}$ where $\varepsilon_{N H \mid W}=0$, and $\frac{d \ln W_{n}}{d \ln H}=-\frac{\ddot{\mathfrak{y}}_{N C}-\ddot{\mathfrak{g}}^{e}}{\ddot{\mathfrak{z}}_{N C}} \leq-1$. 
working time still reduces productivity, and thus employment, but labour costs are no longer sufficiently lowered to compensate for this.

The impact of reduced working time on labour demand is illustrated in the four-quadrant Figure 2. The north-east panel describes labour demand in terms of remuneration. The north-west quadrant relates remuneration to hourly wages. As the whole figure is in logs, this is a straight line. The south-east panel is the employment identity, and the south-west panel describes once again labour demand, but now in terms of hourly wages. The labour demand curves are concave to the origin as in the right panels of Figure 1. Working time is decreased from $H_{0}$ to $H_{1}$. In the north-east quadrant, the labour demand curve in terms of remuneration $C$ shifts inward, but keeps the same slope (this is the main reason that it will be easier to analyse wage determination in terms of remuneration work than in terms of hourly wages). The curve in the north-west panel shifts to the origin, as hourly wages can increase if remuneration is kept constant. The labour demand curve in terms of hourly wages, as depicted in the south-west quadrant, rotates around the critical wage level $W_{n}$, becoming less elastic. It is assumed that in the original allocation $M$ - say the monopoly union wage $W^{m}$ - working time satisfies $H_{0}>H_{n}$ or alternatively $W^{m}>W_{n}$. Hence at the going hourly wage, reduced hours will increase employment.

Figure 2 considers two extreme cases of working time reduction: First, with full wage compensation, thus constant remuneration $C^{m}$ and second, with constant hourly wage $W^{m}$. At given remuneration $C^{m}$ labour demand is reduced to $N_{c}$ in the north-east quadrant. This is due to the fall in productivity. Hourly wages increase to $W_{c}$, which reduces employment along the rotated labour demand in the south-east quadrant to $N_{c}$. At constant hourly wages, however, employment also becomes cheaper. Therefore it is increased along the rotated labour demand in the south-east quadrant to $N_{w}$. As remuneration falls to $C_{w}$, this also corresponds to a point on the shifted labour demand curve in the north-east quadrant.

The shift from $N^{m}$ to $N_{c}$ is the impact of reduced productivity, which always reduces employment (with elasticity $\varepsilon_{N H \mid C}$ ). The shift from $N_{c}$ to $N_{w}$ is due to the reduction in labour costs and works in the opposite direction (with elasticity $\varepsilon_{N C}$ ). The total impact of (reduced) working time on employment thus crucially depends on the impact on remuneration, to which we turn next.

\subsection{Remuneration}

First, consider the impact of reduced working time on individual and union preferences at given monopoly union remuneration $C^{m}$. This is illustrated in Figure 3, which corresponds to the upper panel of Figure 1, where hours are reduced from $H_{0}$ to $H_{1}$. From the left panel it is obvious that employed workers increase their utility from $U^{m}$ to $U_{1}$. Moreover, their limit remuneration $C^{a}$ falls to $C_{1}^{a}$ due to the increased leisure. The increased utility effect implies that the union can obtain its old utility level $\tilde{\mathrm{A}}^{m}$ with lower employment. Hence the union indifference curve in the right panel shifts towards the left to $\tilde{\mathrm{A}}_{1}\left(H_{0}\right) .{ }^{16}$ Due to the fall in limit remuneration it also shifts downward, say from $\tilde{\mathrm{A}}_{1}\left(H_{0}\right)$ to $\tilde{\mathrm{A}}^{m}\left(H_{1}\right)$.

More important, the union indifference curve rotates. Differentiating the left-hand side of the firstorder condition (9) with respect to hours, it can be shown that the union indifference curves become steeper if (and only if)

16 With the old working time, this combination of $C$ and $N$ would yield union utility $\tilde{\mathrm{A}}_{1}\left(H_{0}\right)<\tilde{\mathrm{A}}^{m}$. 


$$
U_{C H}-\frac{U_{C} U_{H}}{U-U^{a}}>0
$$

The left-hand side cannot be signed unambiguously. It is positive if consumption and leisure are Edgeworth substitutes $\left(U_{C H}>0\right)$, but could be negative if consumption and leisure are Edgeworth complements $\left(U_{C H}<0\right)$. Condition (7), however, is a sufficient condition for the expression to be positive. This implies that the union indifference curves in Figure 3 become steeper, compare $\tilde{\mathrm{A}}_{1}\left(H_{0}\right)$ and $\tilde{\mathrm{A}}^{m}\left(H_{1}\right)$.

Combining the effects of the changes in labour demand and union utility in Figures 2 and 3, we can derive the impact on remuneration. Merging the two figures gives a rather blurred picture, yielding no further insight. But as the monopoly remuneration is determined by tangency between labour demand and union utility, see equation (9), it is only the change in the slopes of labour demand and union utility that matter, and not the change in their positions. At given remuneration the labour demand elasticity is unaffected by a work-sharing policy, but the indifference curve becomes steeper. Hence there is an incentive to reduce remuneration.

This effect also occurs in the right-to-manage model. Totally differentiating equation (11) we obtain the partial equilibrium elasticity

$$
\varepsilon_{C H \mid U^{a}}=\frac{H}{\ddot{\mathrm{E}}_{C} U_{C}}\left(U_{C H}-\frac{U_{C} U_{H}}{U-U^{a}}\right)=\left(a_{C H}+\grave{\mathrm{u}} \mu_{C}\right) / \ddot{\mathrm{E}}_{C}>0 .
$$

The second-order condition guarantees that $\ddot{\mathrm{E}}_{C}>0$. Hence the sign is determined by the expression in (15). Thus, given the outside option, the right-to-manage union model indicates that working time reduction leads to wage moderation, in the sense that total remuneration will fall. Through the value of leisure, no full wage compensation is needed. This is true unless consumption and leisure are sufficiently strong Edgeworth complements.

The impact of bargaining power on wage moderation, can be found by differentiating with respect to wage resistance $\mu_{C}$. Its sign is given by the sign of $\ddot{\mathbf{y}}_{C}+\ddot{\mathbf{y}}_{C}$. This expression is often encountered in the sequel. The slope of desired hours is inversely related to the sign of $\ddot{\mathbf{y}}_{C}$, whereas the labour demand model implies that $\ddot{\boldsymbol{y}}_{C}>0$. As the available evidence suggests that desired hours are rather inelastic, it seems reasonable to assume $\ddot{\mathrm{y}}_{C}+\ddot{\mathrm{y}}_{C}>0$. This implies that right-to-manage bargaining models lead to more wage moderation than the monopoly union model.

The short-run model yields a similar expression as (16), only replacing wage resistance $\mu_{C}$ by its short-run counterpart $\mu_{C \mid K}$. As $\mu_{C \mid K}<\mu_{C}$ this implies that wage moderation is also stronger in the longrun model.

The coefficient ù is the slope of the indifference curve in the left panel of Figure 3. As ù increases with working time this suggests that the amount of wage moderation is reduced as working time falls. This is further analysed looking at hourly wages. 


\subsection{Hourly wages}

The impact on hourly wage is less clear-cut. A graphical analysis gives a rather messy figure, with most curves rotating and shifting. Moreover, the basic intuition was already provided in Figures 2 and 3. By definition the partial equilibrium elasticity of hourly wages with respect to working time satisfies $\varepsilon_{W H \mid U^{a}}$ $=\varepsilon_{C H \mid U^{a}}-1$. Using (16) and collecting terms, yields

$$
\varepsilon_{W H \mid U^{a}}=\left[\left(1-\dot{a}_{C}+a_{C H}\right)-\mu_{C}(1-\grave{u})-\ddot{\mathbf{y}}_{C}\right] / \ddot{E}_{C} \text {. }
$$

The numerator of this elasticity consists of three (composite) parts, compared to the seven separate terms identified by Calmfors (1985). ${ }^{17}$ This gives a more intuitive interpretation. The first part corresponds to the sign of the derivative of the desired hours curve $H^{s} .{ }^{18}$ If it is upward sloping, a decrease in working time can be accommodated by a decrease in the hourly wage, to stay in line with desired hours. The opposite holds for a backward sloping curve $H^{s}$. The second part measures the discrepancy between the actual and desired working time, as ù $\lessgtr 1$ for $H \lessgtr H^{s}$. On the one hand, a reduction in working time is valuable for overemployed workers $\left(H>H^{s}\right)$, and hence the hourly wage can be reduced by this mechanism. On the other hand, underemployed workers demand a wage increase to compensate for the additional disutility. This second term thus creates a U-shaped pattern between hourly wages and working time, the minimum being at labour supply. The final term in (17) captures the sensitivity of employment to wage changes. As was illustrated in the south-west panel of Figure 2, a reduction in working time makes the labour demand curve (in terms of hourly wages) more inelastic. This creates an upward pressure on hourly wages.

The joint impact of these three elements in (17) is ambiguous. Figure 4 provides an illustration, assuming inelastic supply $H^{s}$, i.e. in the absence of the first term. The lower curve is the outside option $U=U^{a}$, it has a minimum at $H=H^{s}$. This would be the competitive outcome. This part of the figure is similar to the lower-left panel of Figure 1. Wages will be higher if the union bargains about the wage, this yields the curve labelled $W^{b}$. This curve is U-shaped if the second term in (17) dominates. ${ }^{19}$ The negative third term tilts the whole curve clock-wise, the minimum then being at the right of desired hours, say at $H_{w}>H^{s}$.

The first term in (17) is absent in the figure. It would tilt the $W^{b}$-curve in the opposite direction of the slope of the labour supply curve. Thus a backward sloping supply curve shifts the minimum further to the right, and reduces the likelihood of a positive elasticity $\varepsilon_{W H \mid U^{a}}$. The minimum $H_{w}$ of the U-shaped wage curve remains above $H^{s}$ as long as $\ddot{\mathbf{y}}_{C}+\ddot{\mathrm{y}}_{C}>0$.

The U-shape of the $W^{b}$-curve underscores the conclusion of the previous paragraph that wage moderation (in terms of remuneration) will fall as working time is reduced. Wage moderation of hourly

17 The numerator of equation (17) consists of six separate terms. Rearranging them leads to more or less the same expression as in Calmfors (1985). His seventh term is due to a different specification of the production function. Using a labour services specification, thus ignoring the impact of hours on capital services, would generate another positive term in (17), see footnote 13.

18 Strictly speaking, this is only true for $H=H^{s}$. Rearranging the numerator of (17) the elasticity can be rewritten as $\varepsilon_{W H \mid U^{a}}=\left[-\ddot{\mathbf{u}}_{C}-\left(\dot{a}_{C H}+\grave{u} \mu_{C}\right)(1-\grave{u}) / \grave{u}-\ddot{\mathbf{y}}_{C}\right] / \ddot{E}_{C}$. This illustrates that $\ddot{\mathbf{y}}_{C}$ is the crucial parameter for the first effect.

19 Notice that Calmfors (1985, Fig. 2) also draws a U-shaped pattern for hourly wages. 
wages is much less likely to occur. A similar conclusion was already established by Calmfors (1985). The value added of the present analysis is that full wage compensation is rather unlikely, see the previous subsection. Moreover, the analysis has shown that wage moderation is stronger in a right-tomanage bargaining framework than in a monopoly union model.

\subsection{Employment and welfare}

Having determined the partial equilibrium impact of working time reduction on wages, consider the effects on employment and welfare. For employment two effects work in opposite direction: First, as a direct effect employment is reduced, recall the north-east panel of Figure 2, but second, wage moderation leads to an increase in employment. The latter effect dominates if and only if $\varepsilon_{C H \mid U^{a}}>\mu_{N} \equiv$ $-\varepsilon_{N H \mid C} / \varepsilon_{N C}$. Above I argued that the wage elasticity $\varepsilon_{C H \mid U^{a}}$ is probably increasing in working time. This is illustrated in Figure 5 by the upward sloping $\varepsilon_{C H \mid U^{a}}$-curve. Notice that there is full wage moderation $\left(\varepsilon_{C H \mid U^{a}}=1\right)$ at $H_{w}$. For the right-hand side, notice that $\mu_{N}=1$ at the critical hours $H_{n}$ and $\mu_{N}$ is decreasing in $H$ for the same reason that $H_{n}$ is downward sloping in the hourly wage (see footnote 15 ). This relation is also drawn in Figure 5, with the additional assumption that $H_{n}<H_{w}$. Both curves intersect at $H^{*}$. As a result, employment will increase if working time is long enough $\left(H>H^{*}\right)$, but will decrease for shorter working times. ${ }^{20}$ So there is also an inverted U-shape between employment and working time.

For output $Y$ there is an additional negative direct impact on productivity. So output is more likely to decrease. It can shown to have exactly the same sign distribution as profits Đ. For profits the total effect of working time is given by

$$
\frac{d \ln Ð}{d \ln H}=\varepsilon_{\mathrm{ÐH|C}}+\varepsilon_{\mathrm{ÐC}} \varepsilon_{C H \mid U^{a}}=\frac{1}{1-1}\left[c^{e}-\left(1-\varphi_{V}\right)\left(1-c^{\dagger}\right) \varepsilon_{C H \mid U^{a}}\right]
$$

Reduced working time thus increases profits if and only if $\varepsilon_{C H \mid U^{a}}>\mu_{Ð} \equiv-\varepsilon_{\mathrm{D} H \mid C} / \varepsilon_{\mathrm{DCC}}$. It is easily shown that $\mu_{\mathrm{D}}>\mu_{N}$. Moreover, $\mu_{\mathrm{D}}$ is decreasing in working time. If firms would unilaterally determine working time at given hourly wages, they would choose $H^{d}$ such that $\varepsilon_{\mathrm{D} H \mid C}+\varepsilon_{\mathrm{DC}}=0$, or $\mu_{\mathrm{D}}=1$, see De Regt (1999a). As illustrated in Figure 5, $H^{d}>H_{n}$. Moreover, the two curves $\varepsilon_{C H \mid U^{a}}$ and $\mu_{Ð}$ intersect at $H_{\varnothing}{ }^{21}$ As a result, profits will fall if working time is relatively short $\left(H<H_{ð}\right)$, but increase for longer working times. Once again we have an inverted U-shape for profits and output.

Comparing the employment, output and profit results, there is an interval of working times $\left(H^{*}, H_{ð}\right)$ where a reduction in working time leads to increased employment but to reduced output and profits. Given that employers typically resist work-sharing policies, whereas unions tend to favour them, it seems that currently working time is in that interval.

20 In a short-run labour services model Booth and Ravallion (1993) conclude that a sufficient, but not necessary, condition for a cut in hours to increase employment is that absolute wage elasticity is less than the share of variable labour costs in the wage bill. This can also be interpreted as a lowerbound on working time.

21 There is no a priori reason to order $H_{w}$ relative to $H_{n}$ or $H^{d}$. The only definite orderings are: $H_{n}<H^{d}, H^{*}<$ $H_{\delta}, \min \left[H_{n}, H_{w}\right]<H^{*}<\max \left[H_{n} H_{w}\right]$ and $\min \left[H_{w} H^{d}\right]<H_{\delta}<\max \left[H_{w} H^{d}\right]$. Figure 5 makes the additional assumption that $H_{n}<H_{w}<H^{d}$. 
A reduction in working time has two opposite effects on the utility $U$ of employed workers. First, leisure is increased, but second, as a result of wage moderation, remuneration falls. Totally differentiating the utility rent of employed workers gives, using (16),

$$
\frac{d \ln \left(U-U^{a}\right)}{d \ln H}=\mu_{C}\left(\varepsilon_{C H \mid U^{a}}-\grave{\mathbf{u}}\right)=-\grave{\mathbf{u}} \mu_{C}\left(\ddot{\mathbf{y}}_{C}+\ddot{\mathbf{y}}_{C}\right) / \ddot{\mathrm{E}}_{C} .
$$

The sign depends on the properties of the utility function. Utility will increase as long as $\ddot{\mathbf{y}}_{C}+\ddot{\mathbf{y}}_{C}>0$, as was assumed to hold.

Finally, consider union utility $\tilde{A}$ This will only increase if either employment or individual utility (or both) increase. Using the first-order condition (11), the impact on union utility is

$$
\frac{d \ln \tilde{\mathrm{A}}}{d \ln H}=\grave{\mathrm{è}} \varepsilon_{N C}\left(\varepsilon_{C H \mid U^{a}}-\mu_{N}\right)+\mu_{C}\left(\varepsilon_{C H \mid U^{a}}-\grave{\mathrm{u}}\right) .
$$

The first part on the right-hand side measures the impact on employment and is negative for $H>H^{*}$. The second part measures the impact on the utility rent and most likely negative. So it is impossible to derive definite results. ${ }^{22}$ However, notice that, as $\mu_{C} \geq-\mathrm{è}_{N C}$, union utility can only increase due to work-sharing if $-\mathrm{u} \mu_{C}$ dominates the right-hand side expression. This suggests that hours should be long enough. Whether this critical value exceeds $H^{*}$ depends on the properties of the utility function.

This discussion illustrates that the consequences of reduced working time depend on the initial length of the working week. Adverse effects are likely to occur at relatively short hours, whereas gains can be obtained for longer hours. Unfortunately, it is not possible to be more specific the critical length of working times where the adverse effects start to dominate. This brings the issue of the determination of working time to the fore. This goes beyond the present paper, but see De Regt (1999a). Calmfors (1985), for example, considers the case where the union sets the working time. In that case, workers are underemployed, and we are likely to find rather adverse effects.

\section{Efficient bargaining}

The next question is whether the qualitative results change if we allow for bargaining over employment. So I turn to the class of efficient union bargaining models. Booth and Schiantarelli (1987) also analyse a cut in working time within such a set-up. They conclude that the employment outcome is ambiguous, but likely to be negative, but do not discuss the impact on remuneration.

The solution of the efficient bargaining model can be derived maximizing the log of the Nashmaximand (10) with respect to capital, employment and remuneration. The first-order conditions for a maximum are, respectively

22 In the monopoly union model we can use the envelope theorem to simplify to $\frac{d \ln \tilde{A}^{m}}{d \ln H}=\grave{e} \varepsilon_{N C}\left(\grave{\mathbf{u}}-\mu_{N}\right)$. So the monopoly union utility increases if (and only if) $\grave{u}>\mu_{N}$. Once again this will only be satisfied if working time is long enough. 


$$
\begin{aligned}
& 0=\frac{\partial \ln \grave{\mathrm{U}}}{\partial K}=\frac{\hat{\mathrm{a}}}{\mathrm{Ð}}\left\{\hat{1} e(H)^{\hat{1}} N^{\hat{1}-1} f(k)^{\hat{1}-1} f^{\prime}(k)-R\right\}, \\
& 0=\frac{\partial \ln \grave{U}}{\partial N}=\frac{\grave{\mathrm{e}}}{N}+\frac{\hat{\mathrm{a}}}{\mathrm{Ð}}\left\{\hat{1} e(H)^{1} N^{\hat{1}-1} f(k)^{\hat{1}-1}\left[f(k)-k f^{\prime}(k)\right]-(V+C)\right\}, \\
& 0=\frac{\partial \ln \grave{\mathrm{U}}}{\partial C}=\frac{U_{C}}{U-U^{a}}-\frac{\hat{\mathrm{a} N}}{\mathrm{D}} .
\end{aligned}
$$

Rearranging equations (19) and (20) the optimal capital labour ratio is now determined as

$$
\frac{\mathfrak{i}^{\prime}(\grave{\mathrm{e}}+\hat{\mathrm{a}}) f^{\prime}(k)}{(\grave{\mathrm{e}}+\hat{\mathrm{a}} \hat{1}) f(k)-\hat{\mathbf{1}}(\grave{\mathrm{e}}+\hat{\mathrm{a}}) k f^{\prime}(k)}=\frac{R}{V+C} \text {. }
$$

Comparing this expression with (4), one can show that the optimal capital-labour ratio $k^{E B}$ in the efficient bargaining model is lower than in the right-to-manage model. As before, it is scale independent and does not depend directly on the working time. Given $k^{E B}$, equation (19) can be used to derive the employment level $N^{E B}$. So the model can be interpreted as follows, unions and firms bargain over the manning ratios, but given this choice of technology the firm chooses its scale in an optimal way, see Johnson (1990).

Differentiating (19) and (22) the wage elasticity of labour demand for the efficient bargaining model is given by

$$
\varepsilon_{N C}^{E B}=-\hat{\mathbf{i}}\left(1-\varphi_{V}\right)\left[\hat{o}\left(1-c^{f}\right)+o ́ c^{f}\right]<0,
$$

where

$$
\hat{\imath} \equiv \frac{\sigma_{\hat{a}}\left(1-c_{\zeta}^{f}\right)+c_{\zeta}^{f}}{\sigma_{\hat{\mathrm{a}}}\left(1-c^{f}\right)+o_{c^{f}}^{f}} \geq 1 \text { for ó } \leq 1 \text {. }
$$

It is tempting to write $\varepsilon_{N C}^{E B}=\hat{\imath} \varepsilon_{N C}$, but this ignores the fact that, due to the lower capital-labour ratio in the efficient bargaining model, the elasticity $c^{f}$ may be higher in the efficient bargaining model. ${ }^{23}$ For a Cobb-Douglas production function, however, the wage elasticity of labour demand is always the same in both models.

On the other hand, the working time elasticity of labour demand at given remuneration is the same in both models, as $\varepsilon_{N H \mid C}^{E B}=1 c^{e} /(1-1)=\varepsilon_{N H \mid C}$. The reason is that the firm determines its optimal scale of operation and working time reduction can be compared with neutral technical regress.

Using equations (19) and (22), the first-order condition (21) for the wage can be rewritten as

23 Moreover, ç ${ }^{f}$ is no longer equal to the capital share in total costs, see Johnson (1990). Due to the inefficient high manning ratio, the capital share falls to $\frac{1(\grave{\mathrm{e}}+\hat{\mathrm{a}})}{\grave{\mathrm{e}}+\hat{1} \hat{\mathrm{a}}} \mathrm{c}^{f}<\mathrm{c}^{f}$. 


$$
\frac{C U_{C}}{U-U^{a}}=\mu_{C}^{E B} \equiv\left(1-\varphi_{V}\right) \text { è }\left[o_{\hat{a}}\left(1-c^{f}\right)+c^{f}\right] \text {. }
$$

This has the same structure as the wage setting equation (11) for the right-to-manage model. The only difference is that wage resistance $\mu_{C}^{E B}$ is defined in a slightly different way for the efficient bargaining model, compare equation (13). Due to the possible difference in the elasticity $\mathrm{c}^{f}$ between both models, it is hard to compare the levels of $\mu_{C}^{E B}$ and $\mu_{C}$, but for the Cobb-Douglas case both expressions are identical. As in the right-to-manage model, wage resistance is increasing in è, â, í and ó, non-decreasing in the capital-labour ratio (at least for ó $\leq 1$ ) and decreasing in the share of quasi-fixed labour costs.

To derive the comparative statics of the efficient bargaining model with respect to working time reduction, differentiate (23) to obtain

$$
\varepsilon_{C H \mid U^{a}}^{E B}=\left(a_{C H}+\grave{u} \mu_{C}^{E B}\right) / \ddot{E}_{C}^{E B},
$$

with

$$
\ddot{\mathrm{E}}_{C}^{E B} \equiv \dot{\mathrm{a}}_{C}+\mu_{C}^{E B}+\dot{\mathrm{y}}_{C}^{E B}-1>0
$$

and

$$
0<\ddot{\mathbf{y}}_{C}^{E B} \equiv \frac{C}{\mu_{C}^{E B}} \frac{d \mu_{C}^{E B}}{d C}=\varphi_{V}+\left(1-\varphi_{V}\right) \frac{(1-\delta)\left(\delta_{\hat{\mathrm{a}}}-1\right) c^{f}\left(1-c^{f}\right)}{\delta_{\hat{\mathrm{a}}}\left(1-c^{f}\right)+\mathrm{o}_{c}^{f}}<1 .
$$

The second-order condition for maximization of the Nash-maximand guarantees that $\ddot{\mathrm{E}}_{C}^{E B}>0$.

Comparing (24) with (16) shows that the partial equilibrium elasticity of remuneration with respect to working time has the same structure in the efficient bargaining model and the right-to-manage model. Both elasticities are positive, at least given condition (15). Hence, once again, the model predicts wage moderation as a consequence of working time reduction.

This wage moderation tends to increase employment. But, as before, there is the opposing direct effect of reduced productivity on employment. The first effect dominates for employment if (and only if) $\varepsilon_{C H \mid U^{a}}^{E B}>-\varepsilon_{N H \mid C^{C}} \varepsilon_{N C}^{E B}$, which is most likely if working time is long enough.

\section{Labour market equilibrium}

The wage bargaining process presented above takes the outside option as given. In the labour market equilibrium, wages in all sectors or firms are set in a similar vein. As a result the outside option $U^{a}$ becomes endogenous. Layard and Nickell (1990) have shown that the general equilibrium results might differ substantially from the partial equilibrium analysis. This is the issue of this section, where I use the right-to-manage model of subsection 2.4, but similar results hold for the efficient bargaining model of the previous section.

Layard, Nickell et al. (1991, Ch. 10) claim that equilibrium unemployment is unaffected by worksharing. However, their model does not incorporate working time and leisure as separate elements. 
Cahuc and Granier (1997) do take this into account, and conclude that equilibrium unemployment is unaffected by work-sharing policies, at least in the absence of unemployment benefits. Including these benefits, unemployment may be affected, although the sign depends on the determination of benefits. Work-sharing leads to higher unemployment if the benefit level is given, but lowers unemployment at given replacement rate. Their model, however, does not incorporate the impact of working time on capital services.

\subsection{Labour supply}

When participating in the labour market, agents are either employed or unemployed. Considering a symmetric equilibrium, all firms provide the same utility level $U(C, H)$ for their workers. When being unemployed, workers get an unemployment benefit $B$, but have more leisure time. ${ }^{24}$ The corresponding utility is given by $U^{b}=U(B, 0)<U(C, H)$. The outside option corresponds to the expected utility when participating in the labour market and is thus given by a weighted average of the utility when working and the utility when unemployed

$$
U^{a}=(1-u) U(C, H)+u U(B, 0)
$$

where $u$ is the unemployment rate.

When deciding to participate, agents compare the expected utility of participation $U^{a}$ with their endowment in utility $U^{e}$. I follow the specification in Cahuc and Granier (1997), assuming that these utility endowments may differ between agents. This may, for example, result from differences in wealth or in family composition. Let $s\left(U^{e}\right)$, with $s^{\prime}(\cdot) \geq 0$, denote the cumulative density of utility endowments in the economy. Individuals will only participate if $U^{a}>U^{e}$. Normalising without loss of generality the number of agents to one, labour supply $S$ - the number of participants and not desired hours $H^{S}$ - is given by $S=s\left(U^{a}\right)$. This is a non-decreasing function of the expected utility level $U^{a}$.

To consider the properties of the labour supply equation, (log-)differentiate, using (25) and the definition of ù , to obtain

$$
d \ln S=\varepsilon_{S}\left[(1-u)(d \ln C-\grave{\mathrm{u}} d \ln H)-\frac{U(C, H)-U(B, 0)}{C U_{C}} d u+\tilde{\mathrm{n}}_{U} u d \ln B\right],
$$

where $\varepsilon_{S} \equiv c^{s} C U_{C} U^{a} \geq 0, c^{s}$ is the elasticity of the density function $s(\cdot)$ and $\tilde{\mathrm{n}}_{U} \equiv B U_{C}(B, 0) /$ $\left[C U_{C}(C, H)\right]>0$ is related to the replacement rate $\tilde{n} \equiv B / C$. So labour supply is an increasing function of remuneration and benefits. The negative impact of unemployment illustrates the discouraged worker effect in the model.

At given remuneration, a reduction in working time increases labour supply, as leisure is valuable. Another mechanism working in the same direction, but not present in this paper, is the effect on nonwage incomes of partners. If working time reduction leads to wage moderation, family incomes are reduced. Such a negative income effect may trigger additional participation of partners, increasing

24 I don't discuss the issue of financing of the benefits. 
labour supply. Finally, notice that at given hourly wages, a cut in hours has an ambiguous effect on labour supply, depending on whether workers are over- or underemployed.

\subsection{Wage determination}

In the partial equilibrium, wage setting depends on the outside option $U^{a}$. In a symmetric general equilibrium, the latter depends on unemployment as in equation (25). Substituting this in the partial equilibrium condition (11) gives the general equilibrium wage setting curve

$$
\frac{C U_{C}(C, H)}{U(C, H)-U(B, 0)}=\mu_{C} u \text {. }
$$

It has the same structure as (11), but with outside option $U^{a}$ replaced by the utility $U^{b}$ of the unemployed and with wage resistance $\mu_{C}$ multiplied by the unemployment rate $u$. As a consequence of this analogy in structure, the comparative statics are roughly similar. For example, higher benefits $B$ increase remuneration, whereas wages decline with higher unemployment or higher wage resistance. These are standard predictions of aggregate wage setting behaviour, see Layard, Nickell et al. (1991).

With respect to the impact of working time on remuneration, the general equilibrium elasticity can be written as

$$
\varepsilon_{C H}=\frac{\left(a_{C H}+\mathrm{u} \mu_{C} u\right)}{\ddot{\mathrm{E}}_{C}-\mu_{C}(1-u)} .
$$

Compared to the partial equilibrium elasticity $\varepsilon_{C H \mid U^{a}}$ in (16) the numerator and the denominator have both decreased. The second-order condition (12) no longer guarantees that the denominator is positive, but it is along the aggregate wage setting curve. ${ }^{25}$ The numerator of (28) is once again ambiguous, and may be negative if consumption and leisure are strong Edgeworth complements. A sufficient, but not necessary, condition to exclude this possibility was given by the class of utility functions in (7). So, for this class of utility functions the analysis predicts that working time reduction will lead to wage moderation, in terms of annual remuneration, in the general equilibrium.

Comparing wage moderation at the partial and at the general equilibrium, notice that $\varepsilon_{C H \mid U^{a}}>\varepsilon_{C H}$ if and only if $\ddot{\mathrm{y}}_{C}+\ddot{\mathrm{y}}_{C}>0$. This corresponds to the condition for employed workers to gain from a cut in working time, see equation (18). The reason is the following: If workers gain due to a cut in working

25 The semi-elasticity of remuneration with respect to unemployment is $\varepsilon_{C u}=-1 /\left\{u\left[\ddot{\mathrm{E}}_{C}-\mu_{C}(1-u)\right]\right\}<0$, with the same expression in the denominator. The denominator is positive for $u=1$, as $\ddot{\mathrm{E}}_{C}>0$. Decreasing unemployment increases wages more at lower unemployment rates. For $u=\left(\mu_{C}-\ddot{\mathrm{E}}_{C}\right) / \mu_{C}$ the increase is infinite. Hence aggregate wage setting implies a lowerbound on the feasible unemployment rate given by

$$
u>u_{\min } \equiv \max \left[0,\left(\mu_{C}-\ddot{\mathrm{E}}_{C}\right) / \mu_{C}\right]=\max \left[0,\left(1-\ddot{\mathbf{y}}_{C}-\dot{a}_{C}\right) / \mu_{C}\right] .
$$

This asymptote is positive for low levels of risk aversion á . 
time, the outside option will increase in the general equilibrium; this in turn increases wage claims and thus reduces wage moderation in the general equilibrium.

Turning to hourly wages, the elasticity (28) implies that

$$
\varepsilon_{W H}=\left[\left(1-\dot{a}_{C}+\dot{a}_{C H}\right)-\mu_{C} u(1-\grave{u})-\ddot{y}_{C}\right] /\left[\ddot{\mathrm{E}}_{C}-\mu_{C}(1-u)\right] .
$$

This expression is rather similar to the partial equilibrium result (17). The same three terms appear: the slope of the hours supply curve; the disequilibrium of hours worked and the change in wage resistance, respectively. The second term still suggests a U-shaped pattern, although flatter than the partial equilibrium relation, which is tilted by the first and last terms. As in Figure 4 the minimum $H_{w}$ occurs to the right of hours supply $H^{s}$, unless the latter is strongly upward sloping.

\subsection{Price setting and aggregate labour demand}

To determine the effect of working time on unemployment, wage setting behaviour should be combined with the aggregate labour demand of firms. Two complications arise compared to the labour demand of individual firms in Sections 2 and 3. First, we should take into account that the aggregate price level may change, second, entry may blur the picture.

First, consider aggregate prices. Given the assumption of constant returns to scale, each firm sets its price $P$ as a mark-up on unit costs $X$, as long-run profit maximization implies $P=X / 1$. As a consequence, the elasticity of price with respect to remuneration is equal to the share of variable labour costs in total cost, so $\varepsilon_{P C}=\left(1-\varphi_{V}\right)\left(1-\mathrm{c}^{f}\right)$, and the elasticity of price with respect to working time is $\varepsilon_{P H \mid C}$ $=-c^{e}$. In a symmetric equilibrium, all firms set this price, reducing the sensitivity of the individual firm demand. ${ }^{26}$ Let the elasticity of the demand shifter $D$ with respect to the aggregate price level be $\hat{\mathrm{o}}_{A}$ and let $\hat{1}_{A} \equiv 1-1 / \hat{\mathrm{o}}_{A}$, then it can be shown that the elasticities of aggregate labour demand are given by

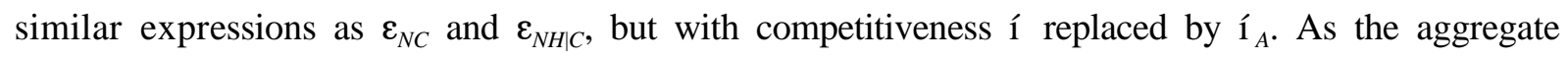
demand is most likely less elastic than firm demand, this makes aggregate labour demand less elastic and less responsive to changes in working time.

Entry would tend to work in the opposite direction, increasing the responsiveness of labour demand. However, entry is difficult to model with constant returns to scale. An alternative solution, leading to similar results, is to replace labour demand in the aggregate equilibrium by price setting behaviour. With constant returns to scale this gives a fully elastic price setting curve, shifting downwards as a consequence of working time reductions. ${ }^{27}$

As Blanchard (1998) has argued, the choice between the above options depends on the perspective of the model: in the short run labour demand is the obvious candidate, but for the longer run, price setting may be better. The link between the two models is quite simple. In the long run, wage and price setting determine the equilibrium real wage. Through the demand shifter $D$, the aggregate labour demand curve,

26 The elasticity ô is best interpreted as the elasticity of firm demand with respect to their relative price. In a symmetric equilibrium the relative price is unity.

27 The impact of working time on price setting is larger than for (aggregate) labour demand, as $-\varepsilon_{P H \mid C} / \varepsilon_{P C}=\mu_{\mathrm{D}}$ $>\mu_{N}$. 
however, depends on the nominal price. In the long-run equilibrium the nominal price will adjust as to guarantee that labour demand and price setting intersect the wage setting curve in the same point.

As the price setting model can be seen as the limiting case of the labour demand model (see footnote 27), I choose the labour demand model to illustrate the general equilibrium impact of reduced working time in the next paragraph. In the numerical example of section 6 is use both models.

\subsection{Equilibrium unemployment}

The aggregate model thus consists of the wage setting equation (27), the aggregate price setting or labour demand curve of the previous paragraph and the labour supply curve (26). Together with the definition of unemployment, $u \approx \ln S-\ln N$, this model determines (real) remuneration $C$, employment $N$, labour supply $S$ and the unemployment rate $u$.

The model is illustrated in Figure 6, where the labour supply is assumed to be inelastic $\left(\varepsilon_{S}=0\right)$. The vertical axis gives (real) annual remuneration and not hourly wages. Using logs, the unemployment rate is simply the difference between supply $s$ and demand $d$. As working time reduction leads to wage moderation, the wage setting curve $w^{b}$ shifts downward. Moreover, labour demand also declines. Both effects reduce the equilibrium remuneration, but the impact on (un-)employment is ambiguous. As a benchmark, the figure considers the case that employment is unaffected.

Solving for the comparative statics, the effects on remuneration and unemployment are ${ }^{28}$

$$
\frac{d \ln C}{d \ln H}=\frac{\varepsilon_{C H}-\varepsilon_{N H \mid C} \varepsilon_{C u}+\varepsilon_{S}\left[\frac{\varepsilon_{C H}}{\mu_{C} u}-(1-u) \grave{\mathrm{u}} \varepsilon_{C u}\right]}{\ddot{\mathrm{E}}_{C u}}>0
$$

and

$$
\frac{d u}{d \ln H}=\frac{-\varepsilon_{N C}\left(\varepsilon_{C H}-\mu_{N}\right)+\varepsilon_{S}(1-u)\left(\varepsilon_{C H}-\grave{u}\right)}{\ddot{\mathrm{E}}_{C u}},
$$

with

$$
\ddot{\mathrm{E}}_{C u} \equiv 1+\varepsilon_{N C} \varepsilon_{C u}+\varepsilon_{S}\left[1 /\left(\mu_{C} u\right)-(1-u) \varepsilon_{C u}\right]>1 .
$$

With inelastic labour supply $\left(\varepsilon_{S}=0\right.$ ), the unemployment rate will fall (and employment will increase) if wage moderation dominates, that is if $\varepsilon_{C H}>\mu_{N}$. A similar condition was established in the partial equilibrium bargaining model, recall Figure 5. In the general equilibrium, the lower elasticity of aggregate demand shifts the $\mu_{N}$-curve to the left, but entry could shift it to the right in the direction of the unchanged $\mu_{\mathrm{D}}$-curve. ${ }^{29}$ The $\varepsilon_{C H^{-}}$-curve shifts downward compared to the partial equilibrium, at least if workers gain from work-sharing ( $\ddot{y}_{C}+\ddot{y}_{C}>0$ ). This leads to an in increase $H^{*}$, but there still exists a U-pattern between the equilibrium unemployment rate and working time. For long working times wage moderation dominates, employment is increased and unemployment falls. For short working times

28 The effect on employment is $\frac{d \ln N}{d \ln H}=\varepsilon_{N C} \frac{\left\{1+\varepsilon_{S}\left[\frac{1}{\mu_{C} u}-(1-u) \varepsilon_{C u}\right]\right\}\left(\varepsilon_{C H}-\mu_{N}\right)+\varepsilon_{S}(1-u) \varepsilon_{C u}\left(\varepsilon_{C H}-\grave{u}\right)}{\ddot{E}_{C u}}$.

29 With pure price setting the aggregate $\mu_{N}$-curve coincides with the $\mu_{\mathrm{D}}$-curve. 
exactly the opposite holds. As employment is unaffected in Figure 6, it is drawn for the critical of working time $H=H^{*}$.

If labour supply, i.e. participation, is elastic another effect is added. As is obvious from equation (26), a cut in working time at given remuneration increases labour supply. This shift of the labour supply curve induces another shift of the wage setting curve, which is defined relatively to the labour supply curve. So remuneration will fall even more. This fall in remuneration increases employment. The effect on the unemployment rate, however, is ambiguous, as both labour supply and labour demand increase. The unemployment rate increases if the utility of employed workers grows (as $\ddot{\mathrm{y}}_{C}+\ddot{\mathrm{y}}_{C}>0$ implies $\varepsilon_{C H}<\grave{u}$ ).

\subsection{Replacement rate}

The above general equilibrium results take the benefit level $B$ of the unemployed as given. In the longer run, it may be more realistic to consider a fixed replacement rate $\tilde{n} \equiv B / C<1$. As working time reduction leads to wage moderation, this suggests that benefits will be reduced. In practice, this may seem an unrealistic assumption. But in an environment with productivity growth, see De Regt (1999a), the only implication is that benefits and remuneration grow at a lower rate in the face of working time reduction.

Taking the fixed replacement rate into account, remuneration is given by

$$
\frac{C U_{C}(C, H)}{U(C, H)-U(\tilde{\mathrm{n}} C, 0)}=\mu_{C} u
$$

In standard wage bargaining models, a constant replacement rate typically implies a vertical wage setting curve, see e.g., Layard, Nickell et al. (1991). This is not the case here. The first reason is that the wage elasticity of employment - or more general wage resistance $\mu_{C}$ - changes with the level of remuneration. The only exception is a Cobb-Douglas production function without quasi-fixed labour costs. The second reason is that the left-hand side may also depend on remuneration, the exception being a Cobb-Douglas utility function. So only with the often used Cobb-Douglas specifications and without quasi-fixed costs, equation (29) defines a unique equilibrium unemployment rate. For this specification, it can be shown that, due to the disutility of working time, equilibrium unemployment will be reduced as a consequence of a cut in working time.

In general, however, equation (29) defines a wage setting curve where remuneration falls if unemployment increases. This curve may shift due to a change in the replacement rate and due to changes in working times. In terms of elasticities, the impact of the latter is

$$
\varepsilon_{C H \mid \tilde{\mathrm{n}}}=\frac{\left(\hat{a}_{C H}+\grave{\mathrm{u}} \mu_{C} u\right)}{\ddot{\mathrm{E}}_{C}-\mu_{C}\left[1-\left(1-\tilde{\mathrm{n}}_{U}\right) u\right]}>\varepsilon_{C H} \text {. }
$$

Compared to (28), only the denominator becomes smaller increasing the impact of reduced working time. This reflects the fact that, at given replacement ratio, benefits will fall as a consequence of the 
wage moderation. The sign remains unaffected, however, and the previous analysis applies only with a reinterpretation of the elasticities of the wage setting curve. As wage moderation is increased, the critical value $H^{*}$ is reduced, and working time reduction is more likely to lead to increased employment.

\section{A numerical illustration}

To illustrate the working of the model, this section provides a numerical illustration of the main effects of a work-sharing policy in the model. The intention is not to provide very realistic outcomes, but to illustrate the main channels operating within the model. Therefore, I use a rather crude calibration of the parameters of the model.

First, consider the model of the firm. For ç ${ }^{f}$, which corresponds to the share of capital costs in total costs, I took 0.3, as in Pissarides (1998). Hart (1984a) documents that the share of quasi-fixed costs in labour costs $\varphi_{V}$ is non-negligible. In line with Hart and Kawasaki (1988), I set $\varphi_{V}=0.2$. As suggested before, the evidence indicates that the substitution elasticity between capital and labour ó is below one, so I adopted ó $=0.5$. Estimates of the elasticity of output with respect to hours are rather imprecise, see Freeman (1998) and Hamermesh (1993). I used $c^{e}=0.6$ as the benchmark, indicating that work-sharing leads to some hourly productivity gains. Moreover, as $\mathrm{ç}^{e}=0.6>0.56=\left(1-\varphi_{V}\right)\left(1-\mathrm{c}^{f}\right)$, firms would like to have longer hours. For the firm specific elasticity of goods demand $\hat{o}$, I used 5.0 as the benchmark. This is within the range adopted by Bovenberg, Graafland et al. (1998) in their applied general equilibrium model for the Netherlands.

These five parameters determine the labour demand elasticities $\varepsilon_{N H \mid C}$ and $\varepsilon_{N C}$ of the partial equilibrium in Table 1. For the short-run model, that is at given capital stock, these elasticities are well within the range of empirical estimates in Hamermesh (1993). Moreover, as $\varepsilon_{N H \mid C}+\varepsilon_{N C}>0$, the calibration implies that work-sharing increases employment at unchanged hourly wages, as in Figure 2. For the long-run model, the labour demand elasticities are rather high. This is due to the choice of $\hat{o}$, leading to large scale effects. That parameter also implies that the mark-up 1/í of prices over marginal (and average) costs is 1.25 , which is rather high. To reduce this mark-up, ô should be increased, but this would further increase the absolute value of the labour demand elasticities.

Second, consider labour supply parameters. For the rate of relative risk-aversion with respect to consumption á ${ }_{c}$, Pissarides (1998) uses 0.8 whereas Teulings and Hartog (1998) suggest a value of roughly 1.25 . I took the intermediate value of $a_{C}=1$. With respect to $a_{C H}$, I am not aware of any sensible estimates. I just assumed that consumption and leisure are neither Edgeworth complements are substitutes, leading to $a_{C H}=0$. These joint assumptions on the utility function imply that $\ddot{\mathrm{y}}_{C}=0$, so desired hours are inelastic. Evidence on workers being over- or underemployed is mixed, see for example OECD (1998). I assumed that workers work less than their desired hours, so the marginal rate of $(\log )$ substitution ù is below one. I adopted ù $=0.9$.

Third, consider the bargaining parameters. The results in Pencavel (1991) indicate that unions care about employment, but estimates vary considerably. I mimicked the results of an utilitarian union utility function, as I set the employment elasticity in union utility è equal to one. Finally, evidence of bargaining power of firms â is scarce. I assumed that both parties have the same power, accordingly I took $\hat{a}=1$, but I also considered the case of a monopoly union $(\hat{\mathrm{a}}=0)$. 
The partial equilibrium results in Table 1, indicate that work-sharing will lead to wage moderation, as the elasticity of remuneration with respect to working time $\varepsilon_{C H}$ is positive. However, hourly wages increase as $\varepsilon_{C H}$ is smaller than one. Wage moderation is stronger in the right-to-manage model than in the monopoly union. Wage moderation is also stronger in the long-run labour demand models, compared to the short-run labour demand model. In both cases this is due to the difference in wage resistance $\mu_{C}$ (not included in the table): Bargaining power increases wage resistance; as does the absolute value of the labour demand elasticity $\varepsilon_{N C}$.

The column labelled ù indicates what the marginal rate of $(\log )$ substitution should be for full wage moderation. This corresponds to minimum $H_{w}$ of the U-shape bargained wage curve in Figure 4. The results indicate that workers should be overemployed (ù $>1$ ) for this to occur.

In the partial equilibrium model, there is no further impact on remuneration $C$, as the outside option is given. So the entries for $\varepsilon_{C H}$ and $C$ are the same. The impact of the work-sharing on employment $N$ differs between the monopoly union model and the right-to manage model. In the former employment is reduced, whereas in the latter employment is increased. The monopoly union model is less favourable, because of its weaker wage moderation. In both cases the elasticities are rather small, however.

The final column considers the critical value of $c^{e} / \mathrm{u}$ where employment does not change as a result of work-sharing. This corresponds to $H^{*}$ in Figure 5. Notice that the ratio $c^{e} / \mathrm{ù} \mathrm{is} \mathrm{decreasing} \mathrm{in} \mathrm{working}$ time, so relative low figures in this column correspond to relative long initial hours. In the benchmark $c^{e} / \mathrm{u}=2 / 3$. In the right-to-manage models the critical values are higher than the benchmark, hence employment increases. With a lower initial working time, however, employment could fall, as in the monopoly union model. This illustrates the inverted U-shape for employment.

The results for the efficient bargaining model are rather similar to the right-to-manage model. The impact on remuneration is almost unchanged, but due to the higher labour demand elasticity, the impact on employment is somewhat more favourable.

Experimenting with different parameter values gives different numbers, but the broad picture remains the same: There is some wage moderation; long-run labour demand models and right-to-manage bargaining lead to stronger wage moderation; right-to-manage and efficient bargaining models have rather similar outcomes; and employment effects tend to be rather limited, the sign depending on the initial working time.

Turning to the general equilibrium, I need to calibrate a four more parameters. The price elasticity of aggregate demand $\hat{\mathrm{o}}_{A}$ is set at 1.5 as in Bovenberg, Graafland et al. (1998). Participation in the labour market is considered to be fully inelastic, so $\varepsilon_{S}=0$. The parameter $\tilde{n}_{U}$ is related to the replacement rate $B / C$, but may be higher due to risk aversion. Ignoring the latter aspect, I used $\tilde{\mathrm{n}}_{U}=0.6$ as in Pissarides (1998), but lower than in Bovenberg, Graafland et al. (1998). Although unemployment is determined within the model, I also needed an initial value as I only consider relative changes. This benchmark value for unemployment $u$ was set at 0.075 , as work-sharing is typically suggested at times of high unemployment.

For given benefits, wage moderation is lower in the general equilibrium than in the partial equilibrium. The reason is that in the partial equilibrium employed workers gain from work-sharing, hence the outside option increases in general equilibrium. This reduces wage moderation. Due to the 
lower price elasticity of goods demand in the aggregate, aggregate labour demand reacts less. Combining the shifts in labour demand and wage setting, see Figure 6, remuneration falls and employment is slightly increased in the labour demand model. The ù -column illustrates that full wage moderation only occurs at very long working times. The last column demonstrates that employment is more likely to increase, compared to the partial equilibrium.

The opposite holds for the price setting model. Here price setting is independent of the scale of production (or employment). As working time $H$ is lower than the demand $H^{d}$ of firms, remuneration declines more than proportionally in the equilibrium. Nevertheless, employment falls. The last column illustrates that initial working time should be rather short to get positive employment effects of worksharing.

If the replacement rate is given, the employment effects are more favourable. Due to wage moderation, benefits also decline reinforcing the positive impact on employment. Notice, however, that the utility of the unemployed falls. Employment still declines in the price setting model, although the critical value for initial hours is reduced.

\section{Concluding remarks}

Working time reduction is a recurrent theme in the European discussion on unemployment. Proponents typically stress the work-sharing aspects, whereas opponents stress the impact on costs and competitiveness. This raises the issue of wage determination in the wake of working time reduction. In this paper I have incorporated these issues in an equilibrium labour market framework. The main conclusions of the analysis are:

- working time reduction is likely to lead to wage moderation in terms of annual remuneration (and this holds for any type of union bargaining framework);

- wage moderation is stronger in right-to-manage models compared to monopoly unions;

- wage moderation is stronger at longer working times;

- there is a U-shaped relation between working times and hourly wages; and, as a consequence,

- there is a U-shaped relation between working times and the equilibrium unemployment rate.

So working time reduction can indeed reduce unemployment, but only for sufficiently long working times. Moreover, a numerical example suggests that the (un-)employment effects are rather limited.

The key then is to determine at what level of working time the impact changes sign. This is on the agenda for future research. From an empirical point of view, the question is whether we can estimate wage setting curves and labour demand or price setting curves with the predicted impact of working times. From a theoretical point of view, the main question is how, and at what level, working times are determined.

\section{References}

Andersen T.M. (1987), Short- and Long-Run Consequences of Shorter Working Hours, pp. 147-165 in Pedersen P.J. and R. Lund (eds.) (1987), Unemployment: Theory, Policy and Structure, Walter de Gruyter, Berlin. 
Blanchard O. (1998), Revisiting European Unemployment: Unemployment, Capital Accumulation and Factor Prices NBER Working Paper 6566, NBER, Cambridge Mass.

Booth A. and M. Ravallion (1993), Employment and Length of the Working Week in a Unionized Economy in which Hours of Work Influence Productivity, The Economic Record, vol. 69, pp. 428436.

Booth A. and F. Schiantarelli (1987), The Employment Effects of a Shorter Working Week, Economica, vol. 54, pp. 237-248.

Bovenberg A.L., J.J. Graafland and R.A. de Mooij (1998), Tax Reform and the Dutch Labor Market: An Applied General Equilibrium Approach, Research Memorandum 143, CPB Netherlands Bureau for Economic Policy Analysis, The Hague.

Broer P., N. Draper and F. Huizinga (1999), The Equilibrium Rate of Unemployment, CPB Report (99/1), pp. 28-33.

Cahuc P. and P. Granier (1997), The consequences of a shorter working time: Some lessons from a general equilibrium analysis, Recherches Economiques de Louvain, vol. 63 (1), pp. 13-32.

Calmfors L. (1985), Work Sharing, Employment and Wages, European Economic review, vol. 27, pp. 293-309.

Calmfors L. and M. Hoel (1989), Work Sharing, Employment and Shiftwork, Oxford Economic Papers, vol. 41, pp. 758-759.

Corneo G. (1994), La Réduction du Temps de Travail dans les Modèles de Chômage d'Équilibre: une Revue de la Littérature, Économie et Prévision, vol. 115, pp. 63-73.

Freeman R.B. (1998), Work-Sharing to Full Employment: Serious Option or Populist Fallacy?, pp. 195-222 in Freeman R.B. and P. Gottschalk (eds.) (1998), Generating Jobs, How to Increase Demand for Less-Skilled Workers, Russell Sage Foundation, New York.

Georgescu-Roegen N. (1970), The Economics of Production, American Economic Review, vol. 60 (Papers and Proceedings), pp. 1-9.

Hamermesh D.S. (1993), Labor Demand, Princeton University Press, Princeton.

Hart R.A. (1984a), The Economics of Non-Wage Labour Costs, Allen \& Unwin, London.

Hart R.A. (1984b), Worksharing and factor prices, European Economic Review, vol. 24, pp. 165-188.

Hart R.A. and S. Kawasaki (1988), Payroll taxes and labour demand, in ?? (ed.) (1988), Research in Labor Economics, JAI Press, Greenwich, Conn.

Hoel M. and B. Vale (1986), Effects on unemployment of reduced working time in an economy where firms set wages, European Economic Review, vol. 30 (5), pp. 1097-1104.

Houpis G. (1993), The Effect of Lower Hours of Work on Wages and Employment, Discussion Paper 131, Center for Economic Performance.

Hunt J. (1998), Hours Reductions as Work-Sharing, Brookings Papers on Economic Activity, vol. 1998 (1), pp. 339-381.

Hunt J. (1999), Has work-sharing worked in Germany?, The Quarterly Journal of Economics, vol. 114 (1), pp. 117-148.

Johnson G.E. (1990), Work Rules, Featherbedding, and Pareto-optimal Union-Management Bargaining, Journal of Labor Economics, vol. 8 (1 supplement), pp. S237-S259. 
Layard R. and S. Nickell (1990), Is Unemployment Lower if Unions Bargain over Employment, Quarterly Journal of Economics, vol. 105, pp. 773-787.

Layard R., S. Nickell and R. Jackman (1991), Unemployment, Macroeconomic Performance and the Labour Market, Oxford University Press, Oxford.

Manning A. (1994), How Robust is the Microeconomic Theory of the Trade Union?, Journal of Labor Economics, vol. 12 (3), pp. 430-459.

Moselle B. (1996), Efficiency wages and the hours/unemployment trade-off 1153, Center for Mathematical Studies in Economics and Management Science, Northwestern University, Evanston.

OECD (1998), Working Hours: latest trends and policy initiatives, pp. 153-188 in OECD (ed.) (1998), Employment Outlook, OECD, Paris.

Pencavel J. (1991), Labor Markets under Trade Unionism, Employment, Wages and Hours, Basil Blackwell, Oxford.

Pissarides C.A. (1998), The impact of employment tax cuts on unemployment and wages; The role of unemployment benefits and tax structure, European Economic Review, vol. 42 (1), pp. 155-183.

de Regt E.R. (1988), Labor Demand and Standard Working Time in Dutch Manufacturing, 1954-1982, pp. 185-205 in Hart R.A. (ed.) (1988), Employment, Unemployment and Labor Utilization, Unwin Hyman, Boston.

de Regt E.R. (1999a), Bargaining over hours, Universiteit Maastricht, Maastricht.

de Regt E.R. (1999b), Labour demand: workers versus hours, Universiteit Maastricht, Maastricht.

de Regt E.R. (1999c), Shiftwork, Operating Time and Working Time (Reduction), Universiteit Maastricht, Maastricht.

Teulings C. and J. Hartog (1998), Corporatism or competition? Labour contracts, institutions and wage structures in international comparison, Cambridge University Press, Cambridge. 
29

Afbeelding 1The monopoly union model
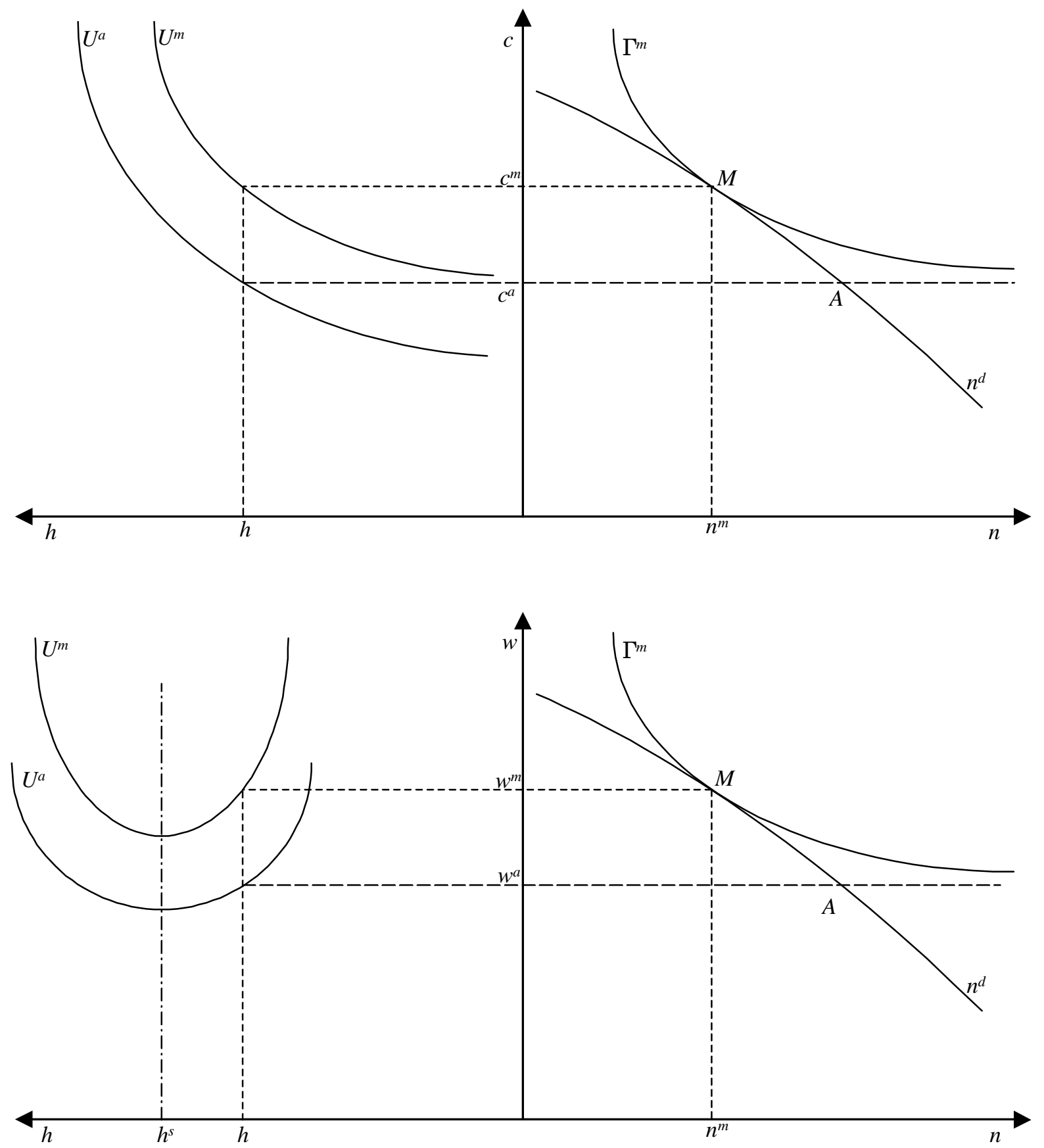
Afbeelding 2Labour demand and working time reduction

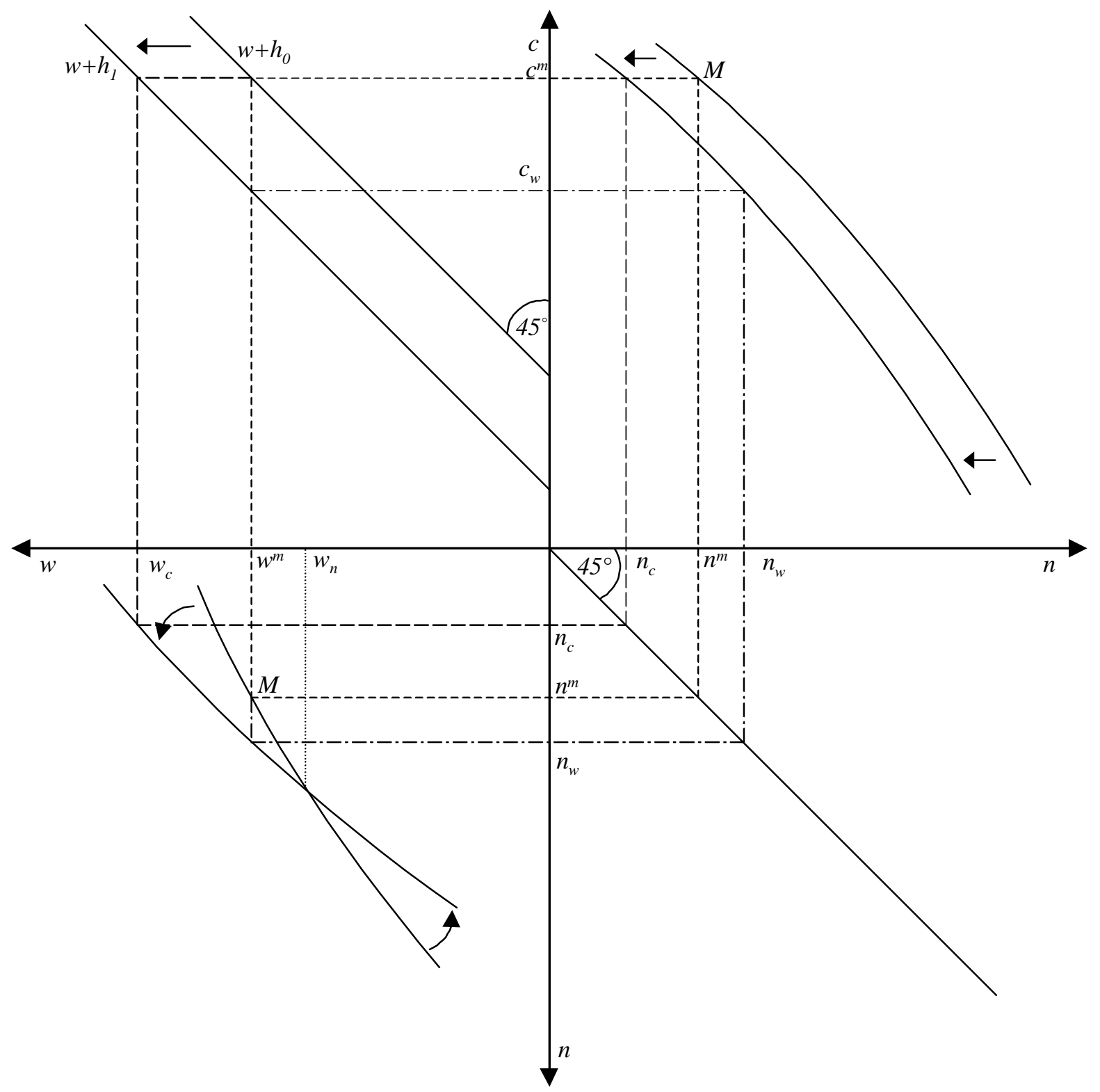


Afbeelding 3Union utility, remuneration and working time reduction

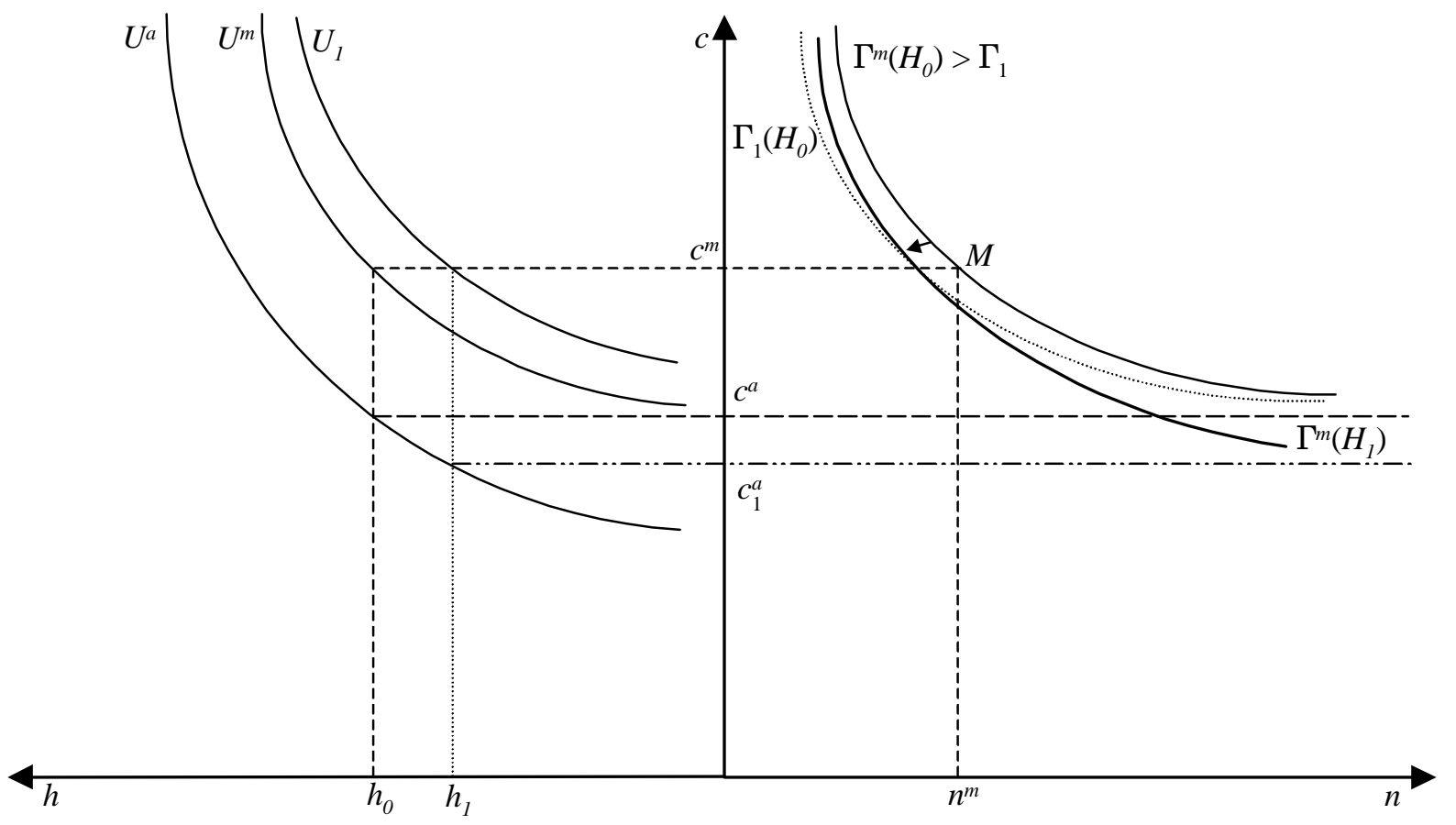

Afbeelding 4Hourly wages and working time

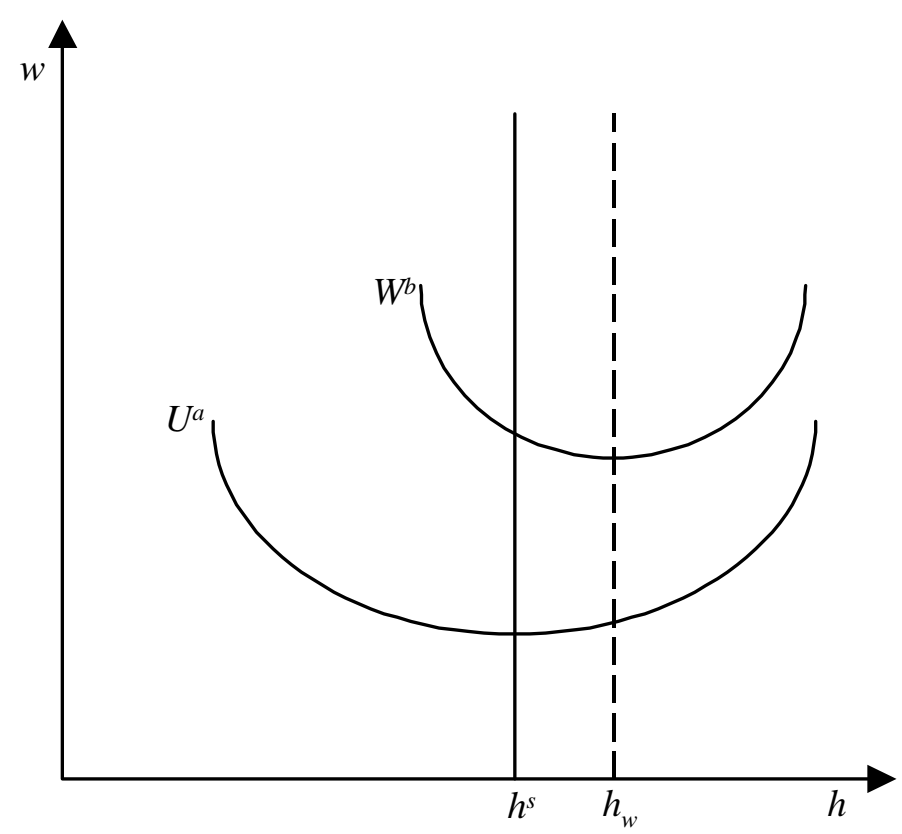


Afbeelding 5Critical working times

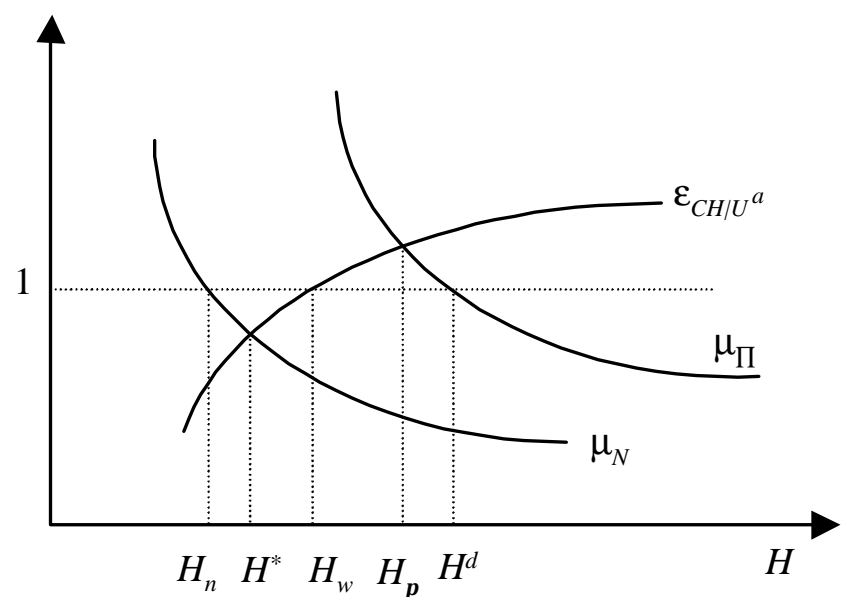

Afbeelding 6Unemployment and working time reduction

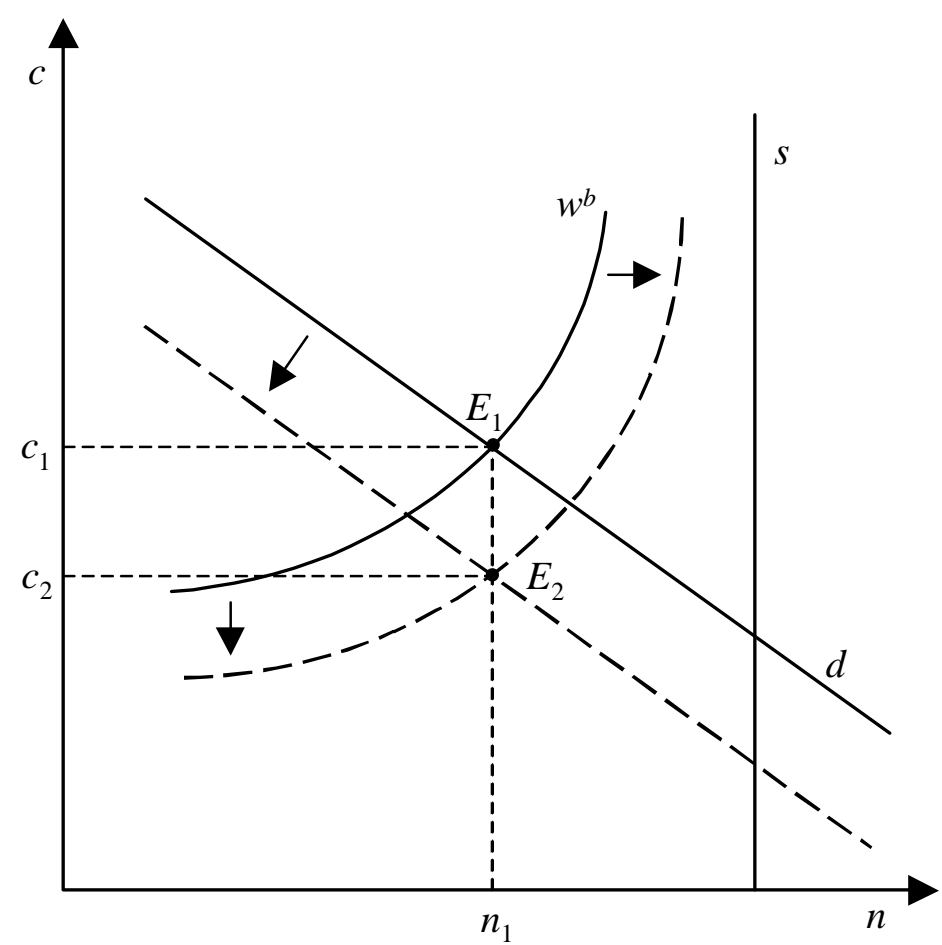


Table $1 \quad$ Numerical working time elasticities

\begin{tabular}{|c|c|c|c|c|c|c|c|}
\hline & $\varepsilon_{N H \mid C}$ & $\varepsilon_{N C}$ & $\varepsilon_{C H}$ & $C$ & $N$ & $\begin{array}{c}\text { ù } \\
\varepsilon_{C H}=1\end{array}$ & $\begin{array}{c}c^{e} / \mathrm{ù} \\
d N=0\end{array}$ \\
\hline \multicolumn{8}{|l|}{ Partial equilibrium $^{\mathrm{a}}$} \\
\hline \multicolumn{8}{|c|}{ Monopoly union $(\hat{\mathrm{a}}=0)$} \\
\hline Short-run labour demand & 0.329 & -0.548 & 0.554 & 0.554 & 0.025 & 1.624 & 0.616 \\
\hline Long-run labour demand & 2.400 & -2.920 & 0.815 & 0.815 & 0.019 & 1.104 & 0.661 \\
\hline \multicolumn{8}{|c|}{ Right-to-manage bargaining } \\
\hline Short-run labour demand & 0.329 & -0.548 & 0.707 & 0.707 & -0.059 & 1.273 & 0.786 \\
\hline Long-run labour demand & 2.400 & -2.920 & 0.849 & 0.849 & -0.079 & 1.060 & 0.689 \\
\hline \multicolumn{8}{|c|}{ Efficient bargaining } \\
\hline Long-run labour demand & 2.400 & -2.988 & 0.851 & 0.851 & -0.143 & 1.058 & 0.706 \\
\hline \multicolumn{8}{|l|}{ General equilibrium $^{\mathrm{b}}$} \\
\hline \multicolumn{8}{|c|}{ Benefits given } \\
\hline Labour demand & 0.600 & -1.240 & 0.499 & 0.322 & -0.009 & 1.803 & 1.065 \\
\hline Price setting & $\infty$ & $\infty$ & 0.499 & 1.071 & 0.030 & 1.803 & 0.311 \\
\hline \multicolumn{8}{|c|}{ Replacement rate given } \\
\hline Labour demand & 0.600 & -1.240 & 0.748 & 0.328 & -0.015 & 1.203 & 1.596 \\
\hline Price setting & $\infty$ & $\infty$ & 0.748 & 1.071 & 0.014 & 1.203 & 0.466 \\
\hline
\end{tabular}

a. The parameter values for the partial equilibrium are $\varphi_{V}=0.2, \mathrm{ç}^{e}=0.6, \mathrm{c}^{f}=0.3, \mathrm{o}=0.5, \hat{\mathrm{o}}=5$, è $=1, \hat{\mathrm{a}}=1, \mathrm{a}_{C}=1, \mathrm{a}_{C H}$ $=0$ and ù $=0.9$.

b. The additional parameters for the general equilibrium are $\hat{\mathrm{o}}_{A}=1.5, \varepsilon_{S}=0, \tilde{\mathrm{n}}_{U}=0.6$ and $u=0.075$. 